\title{
A highly nonlinear coupled mode of decadal variability in a mid-latitude ocean-atmosphere model
}

\author{
S. Kravtsov *,1 \\ Department of Mathematical Sciences, University of Wisconsin-Milwaukee, P.O. \\ Box 413, Milwaukee, WI 53201; Phone: 414-229-4934; Fax: 414-229-4907
}

\begin{abstract}
W. K. Dewar
Department of Oceanography, Florida State University, Tallahassee, FL
\end{abstract} 32306-3048

P. Berloff

Physical Oceanography Department, Woods Hole Oceanographic Institute, Woods Hole, MA 02543

J. C. McWilliams

Department of Atmospheric and Oceanic Sciences and Institute of Geophysics and Planetary Physics, University of California-Los Angeles, Los Angeles, CA 90095

\section{Ghil}

Department of Atmospheric and Oceanic Sciences and Institute of Geophysics and Planetary Physics, University of California-Los Angeles, Los Angeles, CA 90095 
and Départment Terre-Atmosphère-Océan and Laboratoire de Météorologie

Dynamique (CNRS and IPSL), Ecole Normale Supérieure, Paris

\begin{abstract}
This study examines mid-latitude climate variability in a model that couples turbulent oceanic and atmospheric flows through an active oceanic mixed layer. Intrinsic ocean dynamics of the inertial recirculation regions combines with nonlinear atmospheric sensitivity to sea-surface temperature (SST) anomalies to play a dominant role in the variability of the coupled system.

Intrinsic low-frequency variability arises in the model atmosphere; when run in a stand-alone mode, it is characterized by irregular transitions between preferred high-latitude and less frequent low-latitude zonal-flow states. When the atmosphere is coupled to the ocean, the low-latitude state occurrences exhibit a statistically significant signal in a broad 5-15-year band. A similar signal is found in the time series of the model ocean's energy in this coupled simulation. Accompanying uncoupled ocean-only and atmosphere-only integrations are characterized by a decrease in the decadal-band variability, relative to the coupled integration; their spectra are indistinguishable from a red spectrum.

The time scale of the coupled interdecadal oscillation is set by the nonlinear adjustment of the ocean's inertial recirculations to the high-latitude and low-latitude atmospheric forcing regimes. This adjustment involves, in turn, SST changes resulting in long-term ocean-atmosphere heat-flux anomalies that induce the atmospheric regime transitions.
\end{abstract}

Key words: inertial recirculations, mid-latitude jet stream, bimodality 


\section{Introduction}

Decades of study have demonstrated the leading-order importance of geostrophic turbulence to the mid-latitude wind-driven ocean circulation. In contrast, few observational and no general circulation model (GCM) studies have considered the atmospheric and hence climatic impact of realistically turbulent, winddriven ocean dynamics. Some conceptual models, on the other hand, provide tentative explanations of observed frequency spectra in the coupled system, thus suggesting intrinsic ocean variability is important to mid-latitude coupled climate dynamics. These conceptual models have included either eddyresolving oceans (Dewar 2001; Simonnet et al. 2003a,b) or eddy-resolving atmospheres (Kravtsov and Robertson 2002; Feliks et al. 2004), but not both. It thus remains unclear if mid-latitude climate variability is affected by the joint presence of realistic turbulence in both media. The objective of the present paper is to examine this possibility in an idealized coupled ocean-atmosphere model.

\subsection{Background}

One of the well known modes of mid-latitude climate variability is the North Atlantic Oscillation (NAO: Wallace 2000). The spatial structure of the NAO is arguably intrinsic to the atmosphere, since NAO-like structures arise in

\footnotetext{
* Corresponding author Email address: kravtsov@uwm.edu (S. Kravtsov ).

1 Additional affiliation: Department of Atmospheric and Oceanic Sciences and Institute of Geophysics and Planetary Physics, University of California-Los Angeles, Los Angeles, CA 90095
} 
atmospheric GCMs subject only to fixed SSTs (Saravanan 1998). The mechanisms that determine NAO variability are, however, not well understood. While many studies have failed to find evidence of mid-latitude coupling, Czaja and Marshall (2001) argued that a 10-30-yr peak in the sea-level pressure spectrum of the NAO index was an imprint on the atmosphere of local ocean dynamics. Other suggestions of coupled mid-latitude ocean-atmosphere patterns appear in the NAO analysis of Deser and Blackmon (1993), as well as in the combined atmospheric sea-level pressure (SLP) and SST analysis of Kushnir (1994). At the least, these analyses imply departures from the "null hypothesis" of passive ocean SST response to atmospheric "white noise," as first articulated by Hasselmann (1976) and Frankignoul and Hasselmann (1977).

The GCM community is divided in its support for local mid-latitude coupling, since atmospheric GCMs have not yet converged in their response to imposed SST anomalies. Studies have argued both for (Rodwell et al. 1999; Mehta et al. 2000) and against (Kushnir and Held 1996; Saravanan 1998) mid-latitude coupling on decadal-to-interdecadal time scales (see Kushnir et al. 2002 for a review).

A dynamical criticism of previous coupled GCM studies is that they are typically conducted at coarse resolutions, a consequence of which is the appearance of relatively smooth, laminar ocean circulations. The ocean, though, is characterized by energetic variability and nonlinear behavior. Holland (1978) first emphasized the role of mesoscale eddies in highly resolved numerical ocean models, a result that following studies have confirmed and expanded (Barnier et al. 1991; Chassignet 1995; Smith et al. 2000). The role of mesoscale variability in maintaining the oceanic inertial recirculations is implicit in observa- 
tions (Hogg 1985) and several theoretical studies (see, for example, Marshall and Nurser 1988), while numerical investigations have illustrated mechanisms supporting intrinsic ocean variability on interannual and decadal scales (Jiang et al. 1995; Speich et al. 1995; McCalpin and Haidvogel 1996; Dijkstra and Katsman 1997; Berloff and McWilliams 1999; Meacham 2000; Simmonet et al. 2003a,b). The clear significance of such turbulence in the ocean calls into question the results of coupled GCM results conducted in the absence of these dynamics.

Conceptual, linear climate models, where atmospheric variability is represented as white noise, have been used to interpret observations and GCM results (Frankignoul 1985; Barsugli and Battisti 1998). Preferred ocean timescales have been introduced either through basin-scale baroclinic wave propagation forced by NAO-like wind stress anomalies (Jin 1997; Weng and Neelin 1998; Neelin and Weng 1999), or by SST anomalies associated with the thermohaline circulation (THC), subject to NAO heat flux patterns (Griffies and Tziperman 1995; Saravanan and McWilliams 1997, 1998). Marshall et al. (2000) unified several linear models in a common framework and argued for their relevance to the NAO. Intrinsic variability can arise in a dynamically linear ocean through temperature advection (Cessi 2000; Gallego and Cessi 2000, 2001; Primeau and Cessi 2001), while others have studied intrinsic THC variability in nonlinear ocean models subject to either idealized or realistic surface boundary conditions (Weaver et al. 1993; Chen and Ghil 1995, 1996; Huck et al. 2001; Kravtsov and Ghil 2004). In all cases, decadal and longer time scales appear in the climate system.

Dewar (2001) studied a fully nonlinear, quasi-geostrophic (QG) ocean model coupled to the conceptual atmospheric model of Marshall et al. (2000). A broad 
spectral SST peak, like the one described by Czaja and Marshall (2001), arose from a competition between intrinsic ocean variability and forced variability driven by the atmosphere. The latter variations, however, were due almost entirely to feedback from the SST anomalies, thus yielding an atmospheric decadal peak, also in agreement with Czaja and Marshall's (2001) observational study. A shortcoming of Dewar's (2001) model was its overly simple atmospheric component. Kravtsov and Robertson (2002), who used a more dynamically active atmosphere, found no substantial ocean role in their idealized coupled model, but their ocean state was not realistically turbulent.

\subsection{This paper}

Given the ambiguity of coupled GCMs results and suggestive results from conceptual models, we aim to study the role of the oceans' intrinsic variability in coupled settings. The objective of this paper is, therefore, to test if the ocean dynamics known to arise from nonlinear, inertial processes, may lead to new modes of coupled model behavior, given a highly nonlinear, bimodal atmosphere. The participation of substantial nonlinearities in both model fluids is critical in that coupled phenomena must compete against the energetic intrinsic variability present in each medium. To compute turbulent flows in a coupled framework, it is necessary, for reasons of numerical cost, to work with simplified equations; we thus use quasi-geostrophy in idealized settings. This approach reduces dynamical completeness, but allows many numerical concerns to be avoided and sensitivity of model results to parameters to be addressed. Moreover, the underlying dynamics of novel phenomena can be thoroughly investigated. 
In a sense, the present model may be thought of as either the Kravtsov and Robertson (2002) coupled QG model in a more nonlinearly active oceanic regime or the turbulent ocean of Dewar (2001) coupled to a more realistic and bimodal atmosphere. We argue that this coupled model supports a novel mode of coupled variability, in which the nonlinear nature of both the atmosphere and the ocean play important roles. Intrinsic variability renders the atmosphere nonlinearly sensitive to ocean SST signals, which are themselves influenced profoundly by the nonlinear ocean's inertial recirculations. The coupled loop is closed by the inertial recirculations transitioning between states dictated by the atmospheric circulation.

The paper is organized as follows. The model is described in this paper's sections 2.1, with references to Appendices A and B. Section 2.2 motivates our choice of certain model parameters; this choice is important for selecting a regime in which coupled variability dominates. The spin-up procedure and control-run climatology are described in section 3. In section 4, we discuss time-dependent coupled behavior. The detailed three-dimensional structure of the dominant interdecadal oscillation is presented in section 5 , where we argue for the determining role of nonlinear ocean dynamics in this variability. Concluding remarks follow in section 6 .

\section{Model formulation}

\subsection{Model description and numerical details}

Our coupled model is similar to that of Kravtsov and Robertson (2002) and Hogg et al. (2003, 2006). Our atmospheric component is identical to that in 
Kravtsov et al. (2005a), occupying a $20480 \mathrm{~km} \times 6000 \mathrm{~km}$, zonally periodic, flat bottom channel with a rigid lid at a height $H_{\mathrm{a}}=10000 \mathrm{~m}$. The channel bottom is divided between a land surface and a $6000 \mathrm{~km} \times 5800 \mathrm{~km}$ rectangular ocean basin of depth $D_{\mathrm{o}}=4000 \mathrm{~m}$ (see Kravtsov et al. 2005a). Both ocean and atmospheric modules of our coupled model are quasi-geostrophic (QG; Pedlosky 1987), with two layers in the atmosphere and three layers in the ocean. These components are coupled to each other through an active oceanic mixed layer with a fixed thickness of $h_{\mathrm{mix}}=50 \mathrm{~m}$.

Details of the model formulation are given in Appendices A and B. The oceanic equations are discretized on a $512 \times 560$ staggered grid for the mixed-layer Eq. (A.12), which governs SST evolution, and on a $513 \times 561$ A-grid for the potential vorticity conservation in the ocean interior. The mass constraints of McWilliams (1977) have been used for the latter and the resolution in the ocean is $10 \mathrm{~km}$. A 4th-order Arakawa (1966) Jacobian, centered differences for vorticities, frictions, temperature advection and diffusion, as well as fully explicit leap-frog time stepping with $\Delta t=20 \mathrm{~min}$ are used. Ocean model is subject to no-normal flow and partial-slip boundary conditions for each layer's oceanic streamfunction $\Psi$ :

$$
\alpha(\Delta x) \Psi_{n n}-(1-\alpha) \Psi_{n}=0
$$

where subscript $n$ denotes the derivative in the direction normal to the lateral boundary, and $\Delta x=10 \mathrm{~km}$ is the ocean grid size. The lowermost ocean layer employs a bottom drag of the form $-k_{\mathrm{o}}^{-1} \nabla^{2} \Psi_{3}$, where $k_{\mathrm{o}}=30$ days. Sensitivities to this parameter are examined in Kravtsov et al. (2006b).

The equations governing the model atmosphere — subject to no-normal flow 
and no-slip conditions on the northern and southern boundaries, as well as to mass and momentum constraints (McWilliams 1977) — are discretized on a $128 \times 41$-grid with a resolution of $160 \mathrm{~km}$ in both $x$ and $y$. They are numerically integrated using centered differences in space and leap-frog time stepping, with $\Delta t=10 \mathrm{~min}$. In all model components, we average the two time levels every 100 time steps to suppress the spurious numerical mode of the leap-frog scheme.

The ocean's forcing in our model has two components: the Ekman pumping component $w_{E}$, given by Eq. (A.13), as well as the diabatic component, represented effectively by the entrainment $w_{\mathrm{D}}$ at the lower interface of the uppermost ocean layer, which is given by (A.18). The diapycnal flux associated with $w_{\mathrm{D}}$ is the sole forcing of the middle ocean layer, and combines with Ekman pumping to determine the net forcing of the upper layer.

Since the oceanic and atmospheric grids do not coincide in either space or time, the integration of the coupled model proceeds as follows. First, the oceanic fields are kept constant and the atmosphere is stepped forward with the small atmospheric time step. During this integration, $w_{\mathrm{E}}, w_{\mathrm{D}}$, and the contributions to the SST equation due to surface fluxes, Ekman advection and entrainment are accumulated on the coarse atmospheric grid, and then averaged over the integration interval. Second, these forcings are interpolated bilinearly onto the fine oceanic grid, geostrophic advection and diffusion of temperature are added, and the oceanic fields are advanced in time with the appropriate, large time step.

Examination of Eq. (A.13) shows that the area integral of Ekman pumping vanishes due to no-flow boundary conditions for the mixed-layer velocities. 
However, this is not the case for the diabatic pumping $w_{D}$. This is because our ocean QG model lacks an explicit THC and thus drifts toward a warmer ocean state. We correct for this drift by introducing a very smiple "THC parameterization." During an initial 100-yr run, the oceanic diabatic forcing due to entrainment is artificially suppressed; that is $w_{\mathrm{D}}$, though nonzero, is not permitted to affect the middle and upper layers' evolution. The adiabatic, wind-driven state of the ocean model is thus spun up as if $w_{\mathrm{D}}$ were zero. Then the adiabatic integration is continued for another $100 \mathrm{yr}$, and the climatological distribution $\overline{w_{\mathrm{D}}}$ of $w_{\mathrm{D}}$ is computed. In a subsequent integration, $\overline{w_{\mathrm{D}}}$ is applied to the ocean's middle-layer forcing as a flux correction, so that $w_{\mathrm{D}}-\overline{w_{\mathrm{D}}}$ replaces $w_{\mathrm{D}}$ in the middle-layer equation.

\subsection{Choice of parameter regime}

Kravtsov et al. (2005a) have shown that in the atmosphere-only version of our model, forced by an idealized, steady SST distribution, two distinct zonal-flow states exist at realistic, low and intermediate values of the surface drag (see also Koo and Ghil 2002). These two states are maintained by the eddies against the surface drag and differ mainly in terms of meridional position of their climatological jets. The system's low-frequency evolution is characterized by irregular transitions between the two states. Atmospheric surface drag appears parameterically in our coupled model at $k^{-1}$ and continues to play a key role governing variability.

The position of the atmospheric jet axis as a function of the surface friction in the Kravtsov et al. (2005a) model is shown in Fig. 1. The climatological jet axis is defined here as the latitude of the maximum zonally averaged zonal 
component of the barotropic velocity. Multiple equilibria in the zonal-mean flow, namely the high-latitude state and the low-latitude state, occur for $k^{-1}>$ 5.9 days.

Linear response of the atmosphere to small oceanically induced SST anomalies is likely to be small (see section 2). However, in the parameter range where bimodality prevails, that is for $k^{-1}>5.9$ day, the atmosphere can exhibit nonlinear sensitivity to SST anomalies, thus raising the possibility of substantial coupled variability. To examine this possibility, we have examined the behavior for $k^{-1}=6.17$ days. This value is consistent with the spin-down times used in GCMs and inferred from observations (Lorenz and Hartmann 2001, 2003), and places our atmospheric model in the bimodal, nonlinear regime.

Finally, the emphasis of the present paper on the ocean inertial recirculations has led us to adopt $\alpha=2 / 3$ in partial-slip boundary conditions (1), which is closer to the free-slip limit; see Haidvogel et al. (1992), Jiang et al. (1995, appendix A) and Ghil et al. (2002a). As a result, our model's climatological ocean state is characterized by a narrow eastward jet, resembling the Gulf Stream or Kuroshio extension; this jet arises from the merger of the two separated western boundary currents and is accompanied by intense inertial recirculations with a transport of around $100 \mathrm{~Sv}$, as observed.

\section{Climatology}

After a model spinup lasting a few hundred model years (see section 2.1), the control integration is continued for $1000 \mathrm{yr}$. In the next three subsections, we discuss the resulting atmospheric, mixed-layer, and oceanic climatology. 


\subsection{Atmospheric climatology}

The atmospheric climatology for the coupled-model simulation with $k^{-1}=$ 6.17 day is shown in Fig. 2. The maximum of the barotropic zonal velocity [panel (a)] is located over land, just east of the ocean basin; this is also where the meridional gradient of the atmospheric temperature field is largest [panel (b)].

The region of the atmospheric model's maximum high-frequency variability, with time scales on the order of a week and shorter (not shown), is located to the east of the jet maximum, while the maximum of the equivalent-barotropic low-frequency variability (10 days and longer) occurs over the ocean; see Kravtsov et al. (2003, 2005a) for details. The latter variability is thus likely to have a strong influence on the ocean circulation.

The atmospheric climatology from this coupled run does not differ markedly from the climatology obtained in the uncoupled, atmosphere-only model for the same parameter values (Kravtsov et al. 2005a). As we shall argue in sections 4 and 5, though, the atmospheric low-frequency variability is modified by the interaction with a variable ocean.

\subsection{Mixed-layer climatology}

The climatological distributions of the mixed-layer-related fields are shown in Fig. 3. SST [panel (a)] is characterized by a sharp front in the region of confluent western boundary currents and their extension into the ocean basin.

This front also appears in the ocean-atmosphere heat exchange [panel (b)]; 
the oceanic heat gain spatial distribution resembles, at least qualitatively, the observed distribution in the mid-latitude Atlantic (Gill 1982; Fig. 2.7). However, the maximum model heat flux to the atmosphere is roughly 100 $\mathrm{W} \mathrm{m} \mathrm{m}^{-2}$, that is, less than the observed, so the model somewhat underestimates net buoyancy exchange.

The climatological Ekman pumping $w_{\mathrm{E}}$ and flux-corrected interior entrainment rate $w_{\mathrm{D}}-\overline{w_{\mathrm{D}}}$ (see section 2.1 ) are shown in panels $(\mathrm{c})$ and $(\mathrm{d})$, respectively. The former has a reasonable spatial structure, and an amplitude of 3-4 $\times 10^{-6} \mathrm{~m} \mathrm{~s}^{-1}$, which is comparable to the values used by Dewar (2001). In contrast, the time-mean interior entrainment rate is small, which shows that the flux correction procedure (Section 2.1) successfully suppresses model climate drift.

\subsection{Ocean climatology}

The time-mean ocean circulation is shown in Fig. 4. The streamfunctions $\Psi_{1}$, $\Psi_{2}$ and $\Psi_{3}$ of the three layers are depicted in panels (a)-(c), respectively, while their thickness weighted sum, $\Psi_{\text {barotr }}$, is shown in panel (d). The circulation in the upper two layers consists of two large, subtropical and subpolar gyres, of which the former is larger and stronger, and a much narrower and weaker tropical gyre. The subtropical and subpolar gyres are separated by a narrow and intense, eastward jet that arises from the merger of the two separated western boundary currents and has a wave-like longitudinal modulation. Lower-layer mean flow is dominated by the inertial recirculations that consist of two intense and highly localized vortices of opposite sign, which lie on either side of the meandering eastward jet, and a weaker vortex further downstream. 
Both the subtropical and subpolar gyres, as well as the inertial recirculations, are seen in the distribution of the total transport [panel $(d)]$, which reaches $90 \mathrm{~Sv}$. These transport values in the inertial recirculations are realistic and indicate that our ocean model operates in a highly inertial, turbulent regime. The area of the inertial recirculation vortices, however, is too small by a factor of 4 to 5, when compared to the North Atlantic. The areal extent of the recirculations is sensitive to ocean bottom drag, with smaller values of drag leading to stronger, and more realistic inertial recirculations (Kravtsov et al. $2006 b)$.

\section{$4 \quad$ Variability}

\subsection{Diagnostics}

In Fig. 5, we plot the time series of two key model quantities from the coupled run. The leading mode of atmospheric variability corresponds to meridional shifts of the zonal-mean jet (Kravtsov et al. 2005a), shown in panel (a). The histogram of this time series (Fig. 6) is strongly non-Gaussian, with the main peak corresponding to the high-latitude atmospheric state, and a smaller and flatter low-latitude maximum. The high-latitude state (see Fig. 5a) is more persistent, but transitions into the low-latitude state are frequent.

The second diagnostic we chose to track the model's variability is the area

averaged total kinetic energy $E_{\mathrm{k}}$ in the ocean $E_{\mathrm{k}} \equiv E_{\mathrm{k}, 1}+E_{\mathrm{k}, 2}+E_{\mathrm{k}, 3}$, where

$$
E_{\mathrm{k}, i}=\frac{1}{\Sigma_{\mathrm{o}}} \iint_{\Sigma_{\mathrm{o}}} \frac{1}{2} \frac{D_{i}}{D_{\mathrm{o}}}\left(\left|\nabla \Psi_{i}\right|\right)^{2} d x d y, \quad i=1,2,3
$$


The time series of $E_{\mathrm{k}, 1}$ is shown in Fig. 5b. Given our interest in the effects of eddies onto the model's variability, the above energy diagnostic of the ocean's variability may be preferable to some type of the gyre-strength-related quantity (for example, maximum value of the barotropic streamfunction), since the former accounts for both large-scale and small-scale flow intensities.

The heavy solid lines in Figs. 5a,b show 5-30-yr band-pass filtered time series of jet position and $E_{\mathrm{k}, 1}$, respectively. Both quantities exhibit significant variability in this band.

\subsection{Spectral analysis}

The transitions from the high-latitude to the low-latitude state and back were irregular in the Kravtsov et al. (2005a) atmosphere-only model and exhibited no distinguished spectral peak. To examine the effects of coupling, we compute the spectra of the atmospheric jet position and ocean kinetic energy time series.

The Fourier spectrum of the jet position is shown in Fig. 7a. We first computed 40-day nonoverlapping box-car averages, resulting in a time series of 9125 points. The spectrum was computed using Welch's averaged periodogram method, by dividing the signal into 512 point segments, which overlap pairwise by one half of their total length. Each of the segments was detrended, and the final spectrum was obtained by averaging over the periodograms for all segments (Oppenheim and Schafer 1989).

We also show in Figs. 7a,b the spectra resulting from uncoupled, atmosphereonly and ocean-only integrations, as well as the coupled results from the model 
that uses a coarser, 20-km resolution and a higher horizontal viscosity of $A_{\mathrm{H}}=$ $1000 \mathrm{~m}^{2} \mathrm{~s}^{-1}$ in the ocean model. In the former two cases, the two subsystems of the modeled climate system were uncoupled at the base of the ocean mixed layer. The atmosphere-only integration used the time-mean distribution of the vertical Ekman and entrainment heat fluxes into the mixed layer, as well as the time-mean geostrophic advection, both taken from the coupled run. The ocean-only integration's forcing is composed of the time-mean $w_{\mathrm{E}}$, as well as a stochastic component based on the coupled-run time series of $w_{\mathrm{E}}$ and $w_{\mathrm{D}}-\overline{w_{\mathrm{D}}}$.

In each of the two panels of Fig. 7, 95\% confidence intervals are shown with respect to the corresponding uncoupled run: atmosphere-only (with the mixed layer) in Fig. 7a and ocean-only in Fig. 7b (red curves in both panels). In Fig. 7a, the coupled and uncoupled spectra are essentially indistinguishable, with a slight excess in the high-resolution coupled run (blue curve) near 10 yr; note also relative deficit of power near $3 \mathrm{yr}$ in the same (high-resolution coupled) run's spectrum. To verify this spectral structure, we also applied to the oceanic and atmospheric time series two complementary methods of spectral analysis: the multitaper method (Thomson 1982, 1990; Mann and Lees 1996) and singular spectrum analysis (Dettinger et al. 1995; Ghil et al. 2002b). These methods provide more accurate detection of periodicity in a given time series; both confirm the presence of a statistically significant neardecadal peak in the coupled model (not shown). The coupling thus seems to modify slightly the very-low-frequency variability of the atmospheric model, by inducing a preference for near-decadal time scales.

In Fig. 7b, this excess variance of the high-resolution, coupled run in the decadal band is both broader and slightly more pronounced than in Fig. 7a. Interestingly, the coupled run with a more moderate resolution in the ocean 
( $\Delta x=\Delta y=20 \mathrm{~km}$; black curve) shows less overall variance at the lowest frequencies, but a much more significant peak at a periodicity of about 4 yr. The higher resolution thus seems to add, overall, decadal variability; the latter masks the clear oceanic signal at 3-5-yr periods apparent in the coarseresolution run. The broad spectral peak in Fig. 7b (blue curve) is thus due to a combination of the decadal and interannual signals.

The interannual variability in our model is associated with a coupled largescale Rossby wave (Goodman and Marshall 1999); this aspect of our model's behavior is studied further in Kravtsov et al. 2006b). In the meantime we conclude that (i) ocean-atmosphere coupling plays a key role in our model's enhanced decadal variability; and (ii) oceanic nonlinearity is essential for the coupled mode to exist, since the major difference between the control and coarse-resolution run is in the much reduced decadal ocean eddy activity in the latter (see Kravtsov et al. 2006b).

The decadal variability in the atmospheric time series represents a slow modulation of the low-latitude state's frequency of occurrence. We support this observation by constructing a synthetic time series of atmospheric jet position retaining only the transitions to the low-latitude state. In the synthetic time series, the jet position is the same as in the original time series at all times when the jet-axis is south of $46 \mathrm{~N}$; in all other instances, the jet position was set to $46 \mathrm{~N}$, so that the high-latitude state's time dependence was suppressed.

The synthetic time series so obtained is shown in Fig. 8a and its Fourier spectrum in Fig. 8b. This spectrum resembles that of the unmodified jetposition time series (Fig. 7a) at low frequencies, including a broad spectral peak near $10 \mathrm{yr}$. It follows that this periodicity is due, indeed, to a certain 
regularity in the atmospheric transitions to the low-latitude state.

\section{Coupled decadal cycle}

We now study three-dimensional spatial patterns and phase relations between oceanic and atmospheric fields associated with the coupled decadal cycle. Three complementary methods have been used: (i) principal component analysis (PCA) of oceanic and atmospheric fields; (ii) composite analysis, in which we constructed three-dimensional composites of the decadal cycle by keying it to the phases of band-pass filtered time series in Fig. 5; and (iii) laggedcovariance analysis. All three types of analysis produce similar spatial patterns of the decadal ocean-atmosphere variability. Lagged-covariance analysis, however, turns out to be most informative, since it shows not only the spatial patterns and phase relations between oceanic and atmospheric variables, but also points explicitly to the broad-band nature of the coupled signal. We therefore show below the results of the latter analysis.

The analysis was performed by regressing various oceanic and atmospheric fields onto the centered and normalized, 5-30-yr band-pass filtered time series of ocean kinetic energy $E_{\mathrm{k}, 1}$ (Fig. 5b, heavy solid line), multiplied by -1 . In the plots to follow, lag 0 corresponds to the state with minimum ocean kinetic energy, while at positive lags the ocean kinetic energy leads the evolution of a given field. Statistical significance was estimated by generating 100 surrogate time series using a three-level linear stochastic model of the raw $E_{\mathrm{k}, 1}$ time series (Kravtsov et al. 2005b). This model is a multi-level extension of a traditional auto-regressive model. The surrogate time series so obtained were then centered, normalized and filtered to emphasize the 5-30-yr band. Regressing 
the filtered surrogates onto model time series, and sorting the resulting fields pointwise by magnitude, provides estimates of statistical significance.

\subsection{Atmospheric fields}

The results of the lagged-covariance analysis for the barotropic zonal velocity are shown in Fig. 9. The evolution of this field is dominated by the northsouth jet migration, which has a slight wavenumber 4 longitudinal modulation. This spatio-temporal pattern corresponds to the leading empirical orthogonal function (EOF) of Kravtsov et al. (2005a), which dominates the atmospheric model's behavior at low frequencies. The cycle seen in Fig. 9 has a slightly more persistent high-latitude phase, with positive anomalies in the northern part of the channel. This appears in the positive amplitudes present at -7.5 , -5 and 2.5 yr. In comparison, negative amplitudes appear at -2.5 and 0 yrs. The development of the low-latitude state at lag -2.5 yr thus precedes the minimum of kinetic energy in the ocean by roughly a quarter of an oscillation period.

The evolution of the atmospheric temperature during the cycle is shown in Fig. 10. Since the leading mode of the atmospheric model's low-frequency variability is equivalent-barotropic (Kravtsov et al. 2005a), the cycle in the atmospheric temperature resembles the behavior of the barotropic streamfunction (not shown), and is consistent with the behavior of the barotropic zonal velocity in Fig. 9. The low-latitude atmospheric state, close to lag 0, is thus dominated by negative temperature anomalies, with a magnitude of $1^{\circ} \mathrm{C}$ over land and of $0.5^{\circ} \mathrm{C}$ over the ocean. The wavenumber 4 pattern is somewhat more pronounced than in Fig. 9 throughout the cycle. 
The decadal cycle in the atmospheric circulation is also reflected in the evolution of the Ekman pumping shown in Fig. 11. The spatio-temporal pattern of the Ekman-pumping anomaly is qualitatively consistent with that used in the theoretical studies of Dewar (2001) and Marshall et al. (2001). The maximum values of $w_{\mathrm{E}}$ anomalies in our model are on the order of $0.5 \times 10^{-6} \mathrm{~m} \mathrm{~s}^{-1}$; these values are, however, smaller than the value of roughly $3 \times 10^{-6} \mathrm{~m} \mathrm{~s}^{-1}$ used in the above studies. This discrepancy is partly due to the latter value representing presumably the entire atmospheric variability, while ours only reflects the anomalies that are associated with the decadal cycle.

In summary, the atmospheric evolution is correlated with the ocean time series at multi-year lags, consistent with the existence of the coupled decadal cycle found by the spectral analysis of section 4 . In particular, the occurrence of lowlatitude atmospheric state precedes the minimum of ocean's kinetic energy by a quarter of the oscillation period.

\subsection{Ocean circulation}

The evolution of the ocean's upper-layer transport is shown in Fig. 12. The large-scale pattern of this variability is consistent with Sverdrup-like response

of the ocean to the shifting atmospheric jet (Figs. 9 and 10) and the associated Ekman pumping anomaly (Fig. 11). The magnitude of these anomalies at lag 0 is on the order of $5 \mathrm{~Sv}$. There are, however, smaller-scale anomalies with larger amplitudes of about $15 \mathrm{~Sv}$. The latter anomalies are entirely dominated by the ocean's inertial recirculations (Fig. 4); these recirculation anomalies have, when averaged over the entire water column, a peak-to-peak amplitude of about $60 \mathrm{~Sv}$ (not shown). 
The cycle begins with a positive recirculation anomaly (lag -7.5), which reaches its maximum at lag -5 . At the same time, the atmospheric jet's position is being shifted toward low latitudes (Fig. 9); thus, the ocean jet lags behind the atmospheric jet in shifting southward. This property of the oceanic jet to be maintained away from the zero wind-stress curl line is due to rectifying effect of fairly slowly decaying ocean eddy field (Berloff 2005).

Finally, however, well-developed eastward jet does starts to decrease in intensity due to changes in the Ekman pumping field (Fig. 11). This decrease in the jet's intensity causes the positive recirculation anomalies to disappear and negative anomalies to develop at lag -2.5 . The following rapid transition of the atmospheric jet into its low-latitude regime and back (Fig. 9) is accompanied by a maximal weakening of recirculation anomalies at lag 0 , subsequent return to a zero-anomaly state (lag 2.5) and development of positive anomalies at lag 5 .

Thus, the oceanic state at lag 0 is characterized by the breakdown of the penetrating eastward jet and an accompanying minimum in the ocean eddy activity. We will argue in section 5.4 that both the relatively slow onset and rapid breakdown of the atmospheric low-latitude regime are triggered by persistent surface heat flux anomalies whose maintenance relies on the above-mentioned ability of ocean eddies to support eastward jet for a few years even in the absence of local atmospheric pumping. The time scale of the oscillation is thus determined by nonlinear ocean adjustment processes; the latter processes also depend on the bottom-drag coefficient (see Kravtsov et al., 2006b). 


\subsection{SST and ocean-atmosphere heat flux}

The SST evolution during the decadal cycle is shown in Fig. 13. The largest SST anomalies are localized in the inertial recirculation regions and near the easward jet. In the composite cycle (not shown), these anomalies have a peakto-peak amplitude of about $4^{\circ} \mathrm{C}$, which is a factor of $2-4$ larger than the observed decadal anomalies. On the other hand, the extrema are rather localized, and averaging our high-resolution results over $2^{\circ} \times 2^{\circ}$ squares, that is, the resolution of the longest observational data sets, reduces the anomalous amplitudes to the observed values. Note that SST anomaly patterns over the course of the model's evolution are very similar to the upper-layer transport anomalies in Fig. 12. This indicates that anomalous entrainment heat fluxes play an important role in creating these SST anomalies. Note also, however, that both time-mean (Fig. 3c) and anomalous (Fig. 11) Ekman pumping has a fairly large-scale pattern, so that relatively small-scale entrainment heat flux anomalies are, in fact, due to the delay in oceanic eastward jet following the shifted atmospheric jet [and we argue this delay is due to ocean eddies, as the eddies are the only agents that can maintain the jet in the absence of the local forcing; see, once again, Berloff (2005) and Kravtsov et al. (2006b)].

SST anomalies result in anomalous ocean-atmosphere fluxes, whose evolution is shown in Fig. 14. The heat-flux anomalies are negatively correlated, overall, with the SST anomalies in Fig. 13. The patterns and strengths of the wind (Fig. 9) and atmospheric temperature (Fig. 10) are inconsistent with the computed SST patterns, thus implying they are maintained by ocean processes. The largest heat-flux anomalies in the composite cycle (not shown) reach as much as $100 \mathrm{~W} \mathrm{~m}^{-2}$ in magnitude and are located, once again, in the inertial- 
recirculation regions and near the eastward jet. They correspond to the lag-0 field in Fig. 14. The opposite-phase anomalies exhibit smaller heat fluxes, on the order of $30 \mathrm{~W} \mathrm{~m}^{-2}$. These persistent flux anomalies have a long-term effect on the atmospheric dynamics and lead to the decadal cycle therein. In particular, the heat-flux anomalies associated with the delayed response of the ocean eastward jet to the shift of the atmospheric jet tend to reinforce the atmospheric shift [see Kravtsov et al. (2006b)].

\subsection{Dynamics of the decadal cycle}

We have argued that the mechanics that select the decadal time scale for the mode involve ocean nonlinear adjustment to variable forcing, a suggestion that can be indirectly supported by showing linear ajustment mechanics are not appropriate. Based on standard linear theory, the time $T_{i}$ necessary for first and second baroclinic planetary waves to cross our ocean basin of width $L_{x}=$ $5120 \mathrm{~km}$ is $T_{i} \equiv L_{x} /\left(\beta R_{\mathrm{d}, i}^{2}\right), i=1,2$, where $R_{\mathrm{d}, i}$ is the corresponding Rossby radius; this estimate yields crossing times around 4 and 12 years, respectively. A delayed oscillator with these delay times would produce oscillations with periods $(2-3) \times T_{i}$, that is $8-12$ yr for the first mode and $24-36$ yr for the second mode. Thus the second mode displays a considerable mismatch in time scale. In addition, second mode is strongly refracted by the mean flow and thus steered away from the area of the inertial recirculations. Finally, second modes have a relatively weak expression at the surface and are therefore less likely to drive advective SST anomalies. Therefore, the present oscillation cannot be governed by linear propagation of second-mode Rossby waves. The linear first mode has a time scale that matches reasonably well with the present coupled 
mode, but the composites of oceanic fields during the decadal cycle show no signs of wave propagation. We conclude, therefore, that the observed decadal time scale of inertial recirculation SST anomalies is not a result of linear planetary wave propagation. Kravtsov et al. (2006b) have shown, moreover, that even longer, interdecadal periods are obtained for more realistic values of the bottom drag.

In contrast, there is intense variability in the highly nonlinear, inertial recirculations. Our results support the following oscillation mechanism (we discuss below only half of the oscillation cycle; the discussion of another half is analogous). Intrinsic atmospheric variability is dominated by the jet shifts back and forth from high-latitude to low-latitude preferred states. When the frequency of the shifts toward low-latitude state is increased, changes in the atmospheric pumping tend to force the oceanic eastward jet shift to the south. However, due to inertia associated with slowly-decaying oceanic eddy field (developed while the ocean has been in its high-latitude state), the ocean jet follows the atmospheric jet shift with a delay of a few years. This creates long-term SST anomalies (due to anomalous entrainment and advective heat fluxes), which in turn cause ocean-atmosphere fluxes that increase the probability of the atmospheric jet to be in its low-latitude state, thereby reinforcing the atmospheric jet shift. Eventually, the eddy field dissipates and the ocean jet follows the atmospheric jet, the heat-flux anomalies that favor low-latitude state thus being removed. Therefore, the probability of the atmospheric jet to transition to high-latitude state increases and the frequency of the shifts toward low-latitude state is decreased. 


\section{Concluding remarks}

\subsection{Summary}

We have studied the mid-latitude climate dynamics of a quasi-geostrophic (QG) ocean-atmosphere model, whose respective components were coupled via an active constant-thickness mixed layer (section 2 ). The ocean component of the model was placed in a turbulent regime by an appropriate choice of lateral and bottom friction, viscous boundary conditions on the side walls, and horizontal resolution. The atmospheric surface friction coefficient was chosen so that the atmosphere-only model exhibited bimodal low-frequency behavior (see Kravtsov et al. 2005a), characterized by irregular transitions between two distinct persistent regimes, with high-latitude and low-latitude zonal-jet states (section 2.2). We have shown that nonlinear ocean dynamics is essential to the modeled mid-latitude climate variability on decadal and longer time scales.

The nonlinear ocean variability in the model is associated with the inertial recirculations, whose long-term mean is dominated by two intense and highly localized vortices of opposite sign, which lie on either side of the meandering eastward jet formed by the merger of the two western boundary currents. These two recirculation vortices are major contributors to the ocean's mass transport (section 3). The inertial recirculation dynamics plays a major role in the model's broad-band decadal variability. The heightened variability in this decadal band is evident in the time series of atmospheric jet position and of the ocean's kinetic energy, with the atmospheric time series leading the kinetic energy of the ocean basin by a quarter of a cycle (section 4). In contrast, atmosphere-only and stochastically forced ocean-only integrations 
are both characterized by a reduced power in the decadal band and do not exhibit statistically significant spectral peaks there, while the coupled model integrations using coarse ocean resolution are dominated by a 3-5-yr peak associated with a coupled Rossby wave.

The atmospheric cycle takes the form of slow modulation in the occurrence frequency of its low-latitude state. The composite cycle is highly nonlinear, with slower changes during its first half, when the atmosphere is preferentially in the high-latitude state, and faster transition to and return from the atmospheric regime that is characterized by frequent low-latitude state occurrences.

In the first part of the cycle, an intense eastward jet develops in the ocean, which penetrates far into the ocean basin, and is accompanied by strengthening of the inertial recirculations. The second part of the cycle involves the breakdown of the oceanic jet into irregular eddies, and collapse of the inertial recirculations (section 5). The time scale of this cycle is determined by the nonlinear adjustment of the ocean to the two distinct atmospheric forcing regimes, during which the eddies maintain the oceanic jet's location for a few years in the absence of the local atmospheric forcing. This creates SST anomalies, which result in long-term anomalous ocean-atmosphere heat fluxes that favor one atmospheric state or the other. Thus, the decadal oscillation in our model is a coupled mid-latitude ocean-atmosphere phenomenon.

\subsection{Discussion}

The coupled ocean-atmosphere cycle identified in the present paper involves two equally important ingredients: (i) nonlinear variability of the wind-driven 
circulation; and (ii) nonlinear sensitivity of the atmospheric flow to the oceaninduced SST anomalies. Following Jiang et al. (1995), Meacham (2000), and Dewar (2001), among others, we have argued that the former plays a significant role in the mid-latitude climate problem. On the other hand, Kravtsov and Robertson (2002) found in a model very similar to ours that the ocean behavior is fairly passive. The main difference between the other models cited and the latter is the more nonlinear ocean regime. In the present paper, we have explored such a highly nonlinear ocean regime, which now produces stronger oceanic variability than in Kravtsov and Robertson (2002). This variability though, depends in an essential way on the highly nonlinear coupling with the atmosphere, unlike the intrinsic gyre modes of Jiang et al. (1995), Speich et al. (1995), Ghil et al (2002a), Simonnet et al. (2003a,b, 2005), and Dijkstra and Ghil (2006). This highly nonlinear coupling was not present in Kravtsov and Robertson's (2002) model either; it arises from our choice of a strongly bimodal parameter regime for the atmospheric component of the model (Kravtsov et al. 2005a). The bimodality provides a mechanism through which the atmosphere can exhibit strong responses to small SST anomalies caused by intrinsic ocean processes. While the existence of multiple zonalflow states in the mid-latitude atmosphere is still a subject of debate, there is some evidence for such dynamics in both the Southern (Koo et al. 2003) and Northern Hemispheres (Kravtsov et al. 2006a).

The nonlinear oscillation studied in this paper is fundamentally different from those studied previously in linear models (Jin 1997; Neelin and Weng 1998; Marshall et al. 2000), where stochastically driven wave propagation is combined with linear feedback of large-scale SST anomalies on the wind stress. It also differs from the intrinsic ocean variability that arises upon combining 
linear planetary waves and nonlinear temperature advection (Cessi 2000; Gallego and Cessi 2000, 2001; Primeau and Cessi 2001). Dewar (2001) explored the effects of intrinsic ocean dynamics on the mid-latitude climate in a setting that involved an ocean component similar to that in our model. His model for the SST feedback on the atmospheric circulation was, however, linear and identical to that used by Marshall et al. (2000). The highly nonlinear, coupled mode studied here was, therefore, not present in Dewar's (2001) model, due to the lack of nonlinear atmospheric dynamics.

The evidence for the existence of decadal coupled mode presented above comes mainly from the comparison of coupled and uncoupled spectra in section 4.2. While the presence of the enhanced spectral power in the high-ocean-resolution coupled run relative to that in uncoupled and low-resolution runs is established with a high degree of statistical significance (due to a fairly long $[\sim 1000 \mathrm{yr}]$ model integrations), the conjectures about the dynamics of the coupled cycle put forward in section 5 need to be further supported. The lagged-covariance analysis performed in that section describes mainly the forced ocean response to the leading atmospheric jet-shifting mode and shows that the time scales of this response are consistent with the decadal cycle. It also points out explicitly the tendency of the ocean jet to respond to the atmospheric jet shifts with a delay, which is at the heart of present model's coupled dynamics. Kravtsov et al. (2006b) complement the present study by conducting additional, coupled and uncoupled experiments run at various resolutions, and exploring the sensitivity of the coupled mode to key model parameters. The analysis of these experiments provides dynamical evidence for the implied importance of the eddy-driven adjustment and quantifies changes in the statistics of the atmospheric states depending on the state of the ocean. 
Acknowledgements. It is a pleasure to thank D. Kondrashov and A. W. Robertson for helpful discussions. We also thank two anonymous reviewers for their thoughtful comments which helped improve the presentation. This research was supported by NSF grant OCE-02-221066 (all co-authors) and DOE grant DE-FG-03-01ER63260 (MG and SK).

\section{A Coupled model details}

\section{A.1 General formulation}

The equation governing each layer $i$ of the ocean and atmosphere is

$$
\frac{\partial}{\partial t} Q_{i}+J\left(\Psi_{i}, Q_{i}\right)=F_{i}-D_{i}
$$

i.e. quasi-geostrophic potential vorticity conservation. The layer potential vorticity $Q_{i}$ and layer streamfunction $\Psi_{i}$ are related by

$$
Q_{i}=\nabla^{2} \Psi_{i}+\beta y+\frac{f_{0}}{g_{i} H_{i}}\left(\Psi_{i-1}-\Psi_{i}\right) \delta_{i, i_{t}}-\frac{f_{o}}{g_{i-1} H_{i}}\left(\Psi_{i}-\Psi_{i+1}\right) \delta_{i, i_{b}}
$$

The symbol $\delta_{i, j}$ denotes the Kronecker delta function and other notation is standard. The indices $i_{b}$ and $i_{t}$ denote bottom and top layer indices, respectively.

Layer forcings are represented by $F_{i}$ and layer thicknesses are given by $H_{i}$. Layer dissipation in the ocean is governed by regular viscosity $D_{i}=A_{\mathrm{h}} \nabla^{4} \Psi_{i}$, where $A_{\mathrm{h}}=200 \mathrm{~m}^{2} \mathrm{~s}^{-1}$; interfacial friction is everywhere neglected. Frictional terms formulation for the atmospheric model is given in the next subsection. 
For the atmosphere, lower and upper thicknesses are $3000 \mathrm{~m}$ and $7000 \mathrm{~m}$, respectively; for the ocean, the thicknesses are $300 \mathrm{~m}, 700 \mathrm{~m}$ and $3000 \mathrm{~m}$. The reduced gravity parameters associated with the oceanic interfaces are $g_{1}=.02$ and $g_{2}=.01$, which yields first and second deformation radii of $46 \mathrm{~km}$ and $29 \mathrm{~km}$. The scalar $f_{0}=10^{-4} \mathrm{~s}^{-1}$ is the Coriolis parameter and $\beta=2 \times 10^{-11} \mathrm{~m}^{-1} \mathrm{~s}^{-1}$ is its meridional gradient.

\section{A.2 Atmospheric model}

The atmospheric model is fully described in Kravtsov et al. (2005a). We repeat this formulation here for the sake of completeness. The equations for the barotropic component $\psi \equiv\left(\Psi_{1} H_{1}+\Psi_{2} H_{2}\right) /\left(H_{1}+H_{2}\right)$ and baroclinic component $\tau \equiv \Psi_{1}-\Psi_{2}$ (subscript 1 refers to the lower layer) of the streamfunction are obtained by forming corresponding linear combinations of Eqs. (A.1) for $i=1$ and $i=2$ :

$$
\begin{aligned}
\frac{\partial q_{\psi}}{\partial t}+J\left(\psi, q_{\psi}\right)=-k \nabla^{2} \psi & -\sum_{n=1}^{3} k^{(n)} \nabla^{2} \psi^{(n)}+A_{\mathrm{H}} \nabla^{6} \psi-h_{1} h_{2}\left[J\left(\tau, q_{\tau}\right)+\frac{k}{h_{1}} \nabla^{2} \tau\right],(\text { A.3 } 3 \text { ) } \\
\frac{\partial q_{\tau}}{\partial t}+\left(h_{2}-h_{1}\right) J\left(\tau, q_{\tau}\right) & =\frac{f_{0}}{H_{\mathrm{a}}} \frac{1}{h_{1} h_{2}} F(x, y ; \tau, \psi)-\frac{h_{2}}{h_{1}} k \nabla^{2} \tau-\sum_{n=1}^{3} k^{(n)} \nabla^{2} \tau^{(n)}+A_{\mathrm{H}} \nabla^{6} \tau \\
& -\left[J\left(\tau, q_{\psi}\right)+J\left(\psi, q_{\tau}\right)+\frac{k}{h_{1}} \nabla^{2} \psi\right] .
\end{aligned}
$$

Here $h_{1} \equiv H_{1} / H_{\mathrm{a}}$ and $h_{2} \equiv H_{2} / H_{\mathrm{a}}\left(H_{\mathrm{a}} \equiv H_{1}+H_{2}\right)$ are dimensionless thicknesses of the lower and upper atmospheric layer, respectively,

$$
q_{\psi}=\nabla^{2} \psi+\beta y, \quad q_{\tau}=\nabla^{2} \tau-\frac{1}{R_{\mathrm{d}}^{2}} \tau
$$

are the barotropic and baroclinic component of the potential vorticity, respectively, while $F$ is the forcing function; $R_{\mathrm{d}}=383 \mathrm{~km}$ is the Rossby radius of 
deformation, $k$ is the bottom drag, $A_{\mathrm{H}}=-1.5 \times 10^{16} \mathrm{~m}^{4} \mathrm{~s}^{-1}$ is the superviscosity coefficient, and $J(A, B) \equiv(\partial A / \partial x)(\partial B / \partial y)-(\partial A / \partial y)(\partial B / \partial x)$ is the Jacobian. Additional damping terms with the characteristic time scales of $\left(k^{(1)}\right)^{-1}=23$ days, $\left(k^{(2)}\right)^{-1}=29$ days, and $\left(k^{(3)}\right)^{-1}=37$ days are included, following Vautard et al. (1988).

The net, incident less reflected, short-wave radiation at the top of the atmosphere $R$, expressed in $\mathrm{W} \mathrm{m}^{-2}$, is

$$
R=190-165 \sin \left(2 y / a_{\mathrm{E}}\right)
$$

where $a_{\mathrm{E}}=6400 \mathrm{~km}$ is the radius of the Earth. We parameterize other heat fluxes through the sea-surface temperature $T_{\mathrm{s}}$ and the atmospheric temperature $T_{\mathrm{a}}$; the latter is proportional to the baroclinic streamfunction $\tau$, as in Kravtsov et al. (2003): positive $\tau$ corresponds to a thicker lower layer and, hence, colder atmospheric temperature.

Over the ocean, the atmospheric forcing function is

$$
F=\frac{1}{\rho_{\mathrm{a}} c_{\mathrm{P}, \mathrm{a}} \Delta \theta_{\mathrm{s}}}\left(O+H_{\mathrm{SL}}-2 B\right)
$$

where $\Delta \theta_{\mathrm{s}}=50 \mathrm{~K}$ is the difference in potential temperature between the layers, $\rho_{\mathrm{a}}=1.27 \mathrm{~kg} \mathrm{~m}^{-3}$ is the representative atmospheric density, and $c_{\mathrm{P}, \mathrm{a}}=$ $1000 \mathrm{~J} \mathrm{~kg}^{-1} \mathrm{~K}^{-1}$ is the atmospheric heat capacity. Neglecting the heat capacity and conductivity of the land surface results in the forcing function

$$
F=\frac{1}{\rho_{\mathrm{a}} c_{\mathrm{P}, \mathrm{a}} \Delta \theta_{\mathrm{s}}}(R-B)
$$

valid over land. 
The atmospheric back radiation $B$ and the outgoing oceanic long-wave radiation absorbed by the atmosphere $O$ are linear functions of $T_{\mathrm{a}}$ and sea-surface temperature $T_{\mathrm{s}}$, respectively (Kravtsov et al. 2003). The heat exchange between the ocean and the atmosphere is parameterized using a standard bulk formula (Gill 1982):

$$
H_{\mathrm{SL}}=\rho_{\mathrm{a}} U\left\{C_{\mathrm{h}} c_{\mathrm{P}, \mathrm{a}}\left[T_{\mathrm{s}}-T_{\mathrm{a}}\right]+C_{\mathrm{e}} L\left[q\left(T_{\mathrm{s}}\right)-q\left(T_{\mathrm{a}}\right)\right]\right\}
$$

Here $L=2.5 \times 10^{6} \mathrm{~J} \mathrm{~kg}^{-1}$ is the latent heat of vaporization of water, $C_{\mathrm{h}}=$ 0.001 and $C_{\mathrm{e}}=0.0015$. The sea-level wind $U$ is computed through the wind stress $\tau^{(\mathrm{x})}, \tau^{(\mathrm{y})}$ as

$$
U=\left[\left(\tau^{(\mathrm{x}) 2}+\tau^{(\mathrm{y}) 2}\right)^{\frac{1}{2}} /\left(\rho_{\mathrm{a}} C_{\mathrm{d}}\right)\right]^{\frac{1}{2}},
$$

where $\tau^{(\mathrm{x})}, \tau^{(\mathrm{y})}$ are found, in turn, through the atmospheric lower-layer velocities $u_{1}, v_{1}$ as

$$
\left\{\tau^{(\mathrm{x})}, \tau^{(\mathrm{y})}\right\}=\rho_{\mathrm{a}} H_{\mathrm{a}} k\left\{u_{1}-v_{1}, u_{1}+v_{1}\right\}
$$

and $C_{\mathrm{d}}=0.0012$. The specific humidity $q(T)$ is determined via the linearized Clapeyron-Clausius equation

$$
q(T)=3.77 \times 10^{-3}(1+0.07 T)
$$

\section{A.3 Mixed-layer model}

A mixed layer is embedded in the uppermost ocean layer. Mixed layer velocities $u$ and $v$ consist of geostrophic and Ekman contributions, the former set by the upper ocean layer pressure field and the latter by the momentum received from 
the atmosphere [the velocities are assumed vertically uniform over the fixed depth of the mixed layer; see Kravtsov and Robertson (2002)]. SST evolution is thus governed by

$$
\frac{\partial}{\partial t} T_{\mathrm{s}}+\frac{\partial}{\partial x}\left(u T_{\mathrm{s}}\right)+\frac{\partial}{\partial y}\left(v T_{\mathrm{s}}\right)-\frac{1}{h_{\text {mix }}} w_{\mathrm{E}} T_{\mathrm{s}}=\frac{\left(F_{\mathrm{s}}+F_{\mathrm{entr}}\right)}{\rho_{\mathrm{o}} c_{\mathrm{P}, \mathrm{o}} h_{\mathrm{mix}}}+K_{\mathrm{H}} \nabla^{2} T_{\mathrm{s}}
$$

where $F_{\mathrm{s}}$ is the surface heat flux, $F_{\text {entr }}$ is the entrainment heat flux through the base of the mixed layer, $c_{\mathrm{P}, \mathrm{o}}=4000 \mathrm{~J} \mathrm{~kg}^{-1} \mathrm{~K}^{-1}$ is the oceanic heat capacity at constant pressure, $K_{\mathrm{H}}=300 \mathrm{~m}^{2} \mathrm{~s}^{-1}$ is the mixed layer's thermal diffusivity, and $F_{\mathrm{s}}$ is the surface heat flux (see Kravtsov et al. 2005a). Insulating conditions are imposed on the side walls of the oceanic basin. The sub mixed layer ocean is set into motion by the pumping through the mixed layer base computed as the net divergence over the mixed layer of $u$ and $v$

$$
w_{\mathrm{E}}=h_{\operatorname{mix}}\left(\frac{\partial u}{\partial x}+\frac{\partial v}{\partial y}\right)
$$

Entrainment is computed using the McDougall and Dewar (1998) parameterization, where net entrainment and Ekman pumping $w_{\mathrm{E}}$ must balance, as required by our constant-depth mixed-layer model. The two-sided entrainment formula is

$$
w_{\mathrm{E}}=E_{\mathrm{ml}}-E_{1},
$$

with entrainment of subsurface water into the mixed layer measured by $E_{\mathrm{ml}}>$ 0 and entrainment of mixed-layer water into the interior by $E_{1}>0$. The latter case implies a heat flux into the ocean interior (see below). The quantities $E_{\mathrm{ml}}$ and $E_{1}$ are defined in the appendix B. 
The entrainment contribution to SST is

$$
F_{\mathrm{entr}}=-\rho_{\mathrm{o}} c_{\mathrm{P}, \mathrm{o}} E_{\mathrm{ml}} \Delta T_{\mathrm{ml}}
$$

and the entrainment heat flux into the oceanic interior is

$$
F_{\text {int }}=\rho_{\mathrm{o}} c_{\mathrm{P}, \mathrm{o}} E_{1} \Delta T_{\mathrm{ml}}
$$

here

$$
\Delta T_{\mathrm{ml}} \equiv T_{\mathrm{s}}-T_{1}
$$

and $T_{1}=10^{\circ} \mathrm{C}$ is the spatially and temporally uniform temperature of the first subsurface ocean layer. Detrainment from the mixed layer combined with heat conservation implies an entrainment $w_{\mathrm{D}}$ at the lower interface of the uppermost ocean layer:

$$
w_{\mathrm{D}} \equiv \frac{F_{\mathrm{int}}}{\rho_{\mathrm{o}} c_{\mathrm{P}, \mathrm{o}} \Delta T_{1}}
$$

here $\Delta T_{1}=5{ }^{\circ} \mathrm{C}$ is the temperature jump across this interface.

\section{B Parameterization of entrainment}

In this appendix, we formulate a parametrization of the entrainment rates $E_{\mathrm{ml}}$ and $E_{1}$ that enter the two-sided entrainment formula (A.14). If the stratification is stable, that is $\Delta T_{\mathrm{ml}}>0$ [see Eq. (A.17)], there is a diffusive contribution $E_{\mathrm{d}}>0$ to $E_{1}$ that is driven by unresolved mixing processes

$$
E_{\mathrm{d}}=\frac{\mu}{\alpha \Delta T_{\mathrm{ml}} D_{1}}\left(1+\frac{\eta_{1}}{D_{1}}\right)
$$


where $\alpha=2 \times 10^{-4} \mathrm{C}^{-1}$ is the thermal expansion coefficient of water, $\mu=$ $10^{-8} \mathrm{~m}^{2} \mathrm{~s}^{-1}$ is related to the vertical diffusivity, $D_{1}=300 \mathrm{~m}$ is the mean thickness of the upper oceanic layer, and $\eta_{1}$ is the vertical displacement of the interior interface of this layer. Thus,

$$
E_{1}=E_{\mathrm{d}}+E_{1}^{\prime} .
$$

Substituting (A.2) into (A.14) gives

$$
w_{\mathrm{E}}+E_{\mathrm{d}}=E_{\mathrm{ml}}-E_{1}^{\prime} .
$$

If $w_{\mathrm{E}}+E_{\mathrm{d}}>0$, then $E_{\mathrm{ml}}=w_{\mathrm{E}}+E_{\mathrm{d}}$ and $E_{1}^{\prime}=0$. Therefore, from (A.2), $E_{1}=E_{\mathrm{d}}$. In the case of $w_{\mathrm{E}}+E_{\mathrm{d}}<0, E_{1}^{\prime}=-\left(w_{\mathrm{E}}+E_{\mathrm{d}}\right), E_{1}=-w_{\mathrm{E}}$, and $E_{\mathrm{ml}}=0$.

Under statically unstable conditions, that is $\Delta T_{\mathrm{ml}}<0$, the diffusive contribution enters the formula for $E_{\mathrm{ml}}$ :

$$
E_{\mathrm{ml}}=E_{\mathrm{d}}+E_{\mathrm{ml}}^{\prime} .
$$

In this case $E_{\mathrm{d}}>0$ is driven convectively and computed as

$$
E_{\mathrm{d}}=-\frac{\mu}{\alpha \Delta T_{\mathrm{ml}} h_{\mathrm{mix}}} .
$$

Using (A.3) to rewrite (A.14) yields

$$
w_{\mathrm{E}}-E_{\mathrm{d}}=E_{\mathrm{ml}}^{\prime}-E_{1} .
$$

For $w_{\mathrm{E}}-E_{\mathrm{d}}>0, E_{\mathrm{ml}}^{\prime}=w_{\mathrm{E}}-E_{\mathrm{d}}, E_{1}=0$ and $E_{\mathrm{ml}}=w_{\mathrm{E}}$. If $w_{\mathrm{E}}-E_{\mathrm{d}}<0$, $E_{1}=-\left(w_{\mathrm{E}}-E_{\mathrm{d}}\right), E_{\mathrm{ml}}^{\prime}=0$ and $E_{\mathrm{ml}}=E_{\mathrm{d}}$. We restrict the diffusion entrainment 
rate to be less than $E_{\mathrm{d}, \max }=2 \times 10^{-5} \mathrm{~m} \mathrm{~s}^{-1}$ in both stable and unstable situations. 


\section{References}

Arakawa, A., 1966. Computational design for long-term numerical integration of the equations of atmospheric motion. J. Comput. Phys., 1, 119-143.

Barnier, B., Hua, B. and C. LeProvost, C., 1991. On the catalytic role of high baroclinic modes in eddy-driven large-scale circulations. J. Phys. Oceanogr., 21, $976-997$.

Barsugli, J.J. and Battisti, D.S., 1998.The basic effects of atmosphere-ocean thermal coupling on midlatitude variability. J. Atmos. Sci, 55, 477-493.

Berloff, P., 2005. On rectification of randomly forced flows. J. Mar. Res., 31, $497-527$.

Berloff, P.S. and McWilliams, J.C., 1999. Large-scale, low-frequency variability in wind-driven ocean gyres. J. Phys. Oceanogr., 29, 1925-1949.

Berloff, P.S. and Meacham, S.P., 1997. The dynamics of an equivalentbarotropic model of the wind-driven circulation. J. Mar. Res., 55, 407-451.

Berloff, P.S. and Meacham, S.P., 1998. The dynamics of a simple baroclinic model of the wind-driven circulation. J. Phys. Oceanogr., 28, 361-388.

Cessi, P., 2000. Thermal feedback on wind stress as a contributing cause of climate variability. J. Climate, 13, 232-244.

Chassignet, E. P., 1995. Vorticity dissipation by western boundary currents in the presence of outcropping layers. J. Phys. Oceanogr., 25, 242-255.

Chen, F. and Ghil, M., 1995. Interdecadal variability of the thermohaline circulation and high latitude surface fluxes. J. Phys. Oceanogr., 25, 25472568.

Chen, F. and Ghil, M., 1996. Interdecadal variability in a hybrid coupled ocean-atmosphere model. J. Phys. Oceanogr., 26, 1561-1578.

Czaja, A. and Marshall, J., 2001. Observations of atmosphere-ocean coupling 
in the North Atlantic. Quart. J. Roy. Meteor. Soc., 127, 1893-1916.

Deser, C. and Blackmon, M. L., 1993. Surface climate variations over the North Atlantic Ocean during winter: 1900-1989. J. Climate, 6, 1743-1753.

Dettinger, M.D., Ghil, M., Strong, C.M., Weibel, W. and Yiou, P., 1995. Software expedites singular-spectrum analysis of noisy time series. Eos, Trans. AGU, 76, pp. 12, 14, 21.

Dewar, W.K., 2001. On ocean dynamics in mid-latitude climate. J. Climate, 14, 4380-4397.

Dewar, W.K., 2003. Nonlinear midlatitude ocean adjustment. J. Phys. Oceanogr., 33, 1057-1081.

Dijkstra, H.A. and Katsman, C.A., 1997. Temporal variability of the quasigeostrophic wind-driven double gyre ocean circulation: Basic bifurcation diagrams. Geophys. Astrophys. Fluid Dyn., 85, 195-232.

Dijkstra, H. A. and Ghil, M., 2006. Low-frequency variability of the large-scale ocean circulation: A dynamical systems approach. Rev. Geophys., in press.

Feliks, Y., Ghil, M., and Simonnet, E., 2004. Low-frequency variability in the mid-latitude atmosphere induced by an oceanic thermal front. J. Atmos. Sci., 61, 961-981.

Frankignoul, C., 1985. Sea surface temperature anomalies, planetary waves and air-sea feedback in middle latitudes. Rev. Geophys., 8, 233-246.

Frankignoul, C. and Hasselmann, K., 1977. Stochastic climate models. Part II: Application to sea surface temperature anomalies and thermocline variability. Tellus, 29, 284-305.

Frankignoul, C., Czaja, A. and L'Heveder, B., 1998. Air-sea interaction in the North Atlantic and surface boundary conditions for ocean models. J. Climate, 11, 2310-2324.

Gallego, B. and Cessi, P., 2000. Exchange of heat and momentum between 
the atmosphere and the ocean: A minimal model of decadal oscillations. Climate Dyn., 16, 479-489.

Gallego, B. and Cessi, P., 2001. Decadal variability of two oceans and an atmosphere. J. Climate, 14, 2815-2832.

Ghil, M., Feliks, Y., and Sushama, L., 2002a. Baroclinic and barotropic aspects of the wind-driven ocean circulation. Physica D, 167, 1-35.

Ghil, M., Allen, M.R., Dettinger, M.D., Ide, K., Kondrashov, D., Mann, M.E., Robertson, A.W., Saunders, A., Tian, Y., Varadi, F., and Yiou, P., 2002b. Advanced spectral methods for climatic time series. Rev. Geophys., 40, 31-3-41, 10.1029/2000GR000092.

Gill, A., 1982. Atmosphere-Ocean Dynamics. Academic Press, 662 pp.

Goodman, J. and Marshall, J., 1999. A model of decadal middle-latitude atmosphere-ocean interaction. J. Climate, 12, 621-641.

Griffies, S. M. and Tziperman, E., 1995. A linear thermohaline oscillator driven by stochastic atmospheric forcing. J. Climate, 8, 2440-2453.

Haidvogel, D.B., McWilliams, J.C. and Gent, P.R., 1992. Boundary current separation in a quasigeostrophic, eddy-resolving ocean circulation model. J. Phys. Oceanogr., 22, 882-902.

Hasselmann, K., 1976. Stochastic climate models. Part I: Theory. Tellus, 28, 289-305.

Hogg, N., 1985. Evidence for baroclinic instability in the Gulf Stream recirculation. Prog. Oceanogr., 14, 209-229.

Hogg, A.M., Dewar, W.K., Killworth, P.D. and Blundell, J.R., 2003. A quasigeostrophic coupled model (Q-GCM). Mon. Wea. Rev., 131, 2261-2278.

Hogg, A.M., Dewar, W.K., Killworth, P.D. and Blundell, J.R., 2006. Decadal variability of the midlatitude climate system driven by the ocean circulation. J. Climate, in press. 
Holland, W., 1978. The role of mesoscale eddies in the general circulation of the ocean - numerical experiments using a wind-driven quasi-geostrophic model. J. Phys. Oceanogr., 8, 363-392.

Huck, T., Vallis, G.K. and Colin de Verdière, A., 2001. On the robustness of the interdecadal modes of the thermohaline circulation. J. Climate, 14, 940-963.

Jiang, S., Jin, F.-F., and Ghil, M., 1995. Multiple equilibria, periodic and aperiodic solutions in a wind-driven, double-gyre, shallow-water model. J. Phys. Oceanogr., 25, 764-786.

Jin, F.-F., 1997. A theory of interdecadal climate variability of the North Pacific ocean-atmosphere system. J. Climate, 10, 1821-1835.

Koo, S. and Ghil, M., 2002. Successive bifurcations in a simple model of atmospheric zonal-flow vacillation. Chaos, 12, 300-309.

Koo, S., Robertson, A.W. and Ghil, M., 2003. Multiple regimes and lowfrequency oscillations in the Southern Hemisphere's zonal-mean flow. J. Geophys. Res., 10.1029/2001JD001353.

Kravtsov, S. and Robertson, A.W., 2002. Midlatitude ocean-atmosphere interaction in an idealized coupled model. Climate Dyn., 19, 693-711.

Kravtsov, S. and Ghil, M., 2004. Interdecadal variability in a hybrid coupled ocean-atmosphere-sea ice model. J. Phys. Oceanogr., 34, 1756-1775.

Kravtsov, S., Robertson, A.W. and Ghil, M., 2003. Low-frequency variability in a baroclinic $\beta$-channel with land-sea contrast. J. Atmos. Sci., 60, 22672293.

Kravtsov, S., Robertson, A.W. and Ghil, M., 2005a. Bimodal behavior in a baroclinic $\beta$-channel model. J. Atmos. Sci., 62, 1746-1769.

Kravtsov, S., Kondrashov, D. and Ghil, M., 2005b. Multiple regression modeling of nonlinear processes: Derivation and applications to climatic variabil- 
ity, 2005b, J. Climate, 18, 4404-4424.

Kravtsov, S., Robertson, A.W. and Ghil, M., 2006a. Multiple regimes and low-frequency oscillations in the Northern Hemisphere's zonal-mean flow. J. Atmos. Sci., 63, 840-860.

Kravtsov, S., Berloff, P., Dewar, W.K., McWilliams, J.C. and Ghil, M., 2006b. Dynamical origin of low-frequency variability in a highly nonlinear mid-latitude coupled model. J. Climate, accepted. Available at http://www.uwm.edu/ kravtsov/publications/.

Kushnir, Y., 1994. Interdecadal variations in North Atlantic sea surface temperature and associated atmospheric conditions. J. Climate, 7, 141-157.

Kushnir, Y. and Held, I., 1996. Equilibrium atmospheric response to North Atlantic SST anomalies. J. Climate, 9, 1208-1220.

Kushnir, Y., Robinson, W.A., Bladé, I., Hall, N.M.J., Peng, S. and Sutton, R., 2002. Atmospheric GCM response to extratropical SST anomalies: Synthesis and evaluation. J. Climate, 15, 2233-2256.

Lorenz, D.J. and Hartmann, D.L., 2001. Eddy-zonal flow feedback in the Southern Hemisphere. J. Atmos. Sci., 58, 3312-3327.

Lorenz, D.J. and Hartmann, D.L., 2003. Eddy-zonal flow feedback in the Northern Hemisphere winter. J. Climate, 16, 1212-1227.

Mann, M.E. and Lees, J.M., 1996. Robust estimation of background noise and signal detection in climatic time series. Clim. Change, 33, 409-445.

Marshall, J., Johnson, H. and Goodman, J., 2000. A study of the interaction of the North Atlantic Oscillation with ocean circulation. J. Climate, 14, 1399-1421.

Marshall, J. and Nurser, G., 1988. On the recirculation of the sub-tropical gyre. Quart. Jour. Roy. Met. Soc., 114, 1517-1534.

McCalpin, J. and Haidvogel, D., 1996. Phenomenology of the low-frequency 
variability in a reduced-gravity, quasigeostrophic double-gyre model. J. Phys. Oceanogr., 26, 739-752.

McDougall, T.J. and Dewar, W.K., 1998. Vertical mixing, cabbeling and thermobaricity in layered models. J. Phys. Oceanogr., 28, 1458-1480.

McWilliams, J.C., 1977. A note on a consistent quasi-geostrophic model in a multiply connected domain. Dyn. Atmos. Oceans, 1, 427-441.

Meacham, S.P., 2000. Low-frequency variability in the wind-driven circulation. J. Phys. Oceanogr., 30, 269-293.

Meacham, S.P. and Berloff, P.S., 1997a. Barotropic, wind-driven circulation in a small basin. J. Mar. Res., 55, 523-563.

Meacham, S.P. and Berloff, P.S., 1997b. Instabilities of a steady, wind-driven circulation. J. Mar. Res., 55, 885-913.

Mehta, V.M., Suarez, M.J., Manganello, J.V. and Delworth, T.L., 2000. Oceanic influence on the North Atlantic Oscillation and associated Northern Hemisphere climate variations: 1959-1993. Geoph. Res. Letts., 27, 121-124.

Münnich, M., Latif, M., Venske, S., and Maier-Reimer, E., 1998. Decadal oscillations in a simple coupled model. J. Climate, 11, 3309-3319.

Neelin, J.D. and Weng, W., 1999. Analytical prototypes for ocean-atmosphere interaction at midlatitudes. Coupled feedbacks as a sea surface temperature dependent stochastic process. J. Climate, 12, 697-721.

Oppenheim, A.V. and Schafer, R.W., 1989. Discrete-Time Signal Processing. Englewood Cliffs, NJ, Prentice-Hall.

Pedlosky, J., 1987. Geophysical Fluid Dynamics. Springer, New York, 621 pp.

Primeau, F., and Cessi, P., 2001. Coupling between wind-driven currents and midlatitude storm tracks. J. Climate, 14, 1243-1261.

Rodwell, M.J., Rodwell, D.P., and Folland, C.K., 1999. Oceanic forcing of the wintertime North Atlantic Oscillation and European climate. Nature, 398, 
$320-323$.

Saravanan, R., 1998. Atmospheric low-frequency variability and its relationship to midlatitude SST variability: Studies using NCAR Climate System Model. J. Climate, 11, 1386-1404.

Saravanan, R. and McWilliams, J.C., 1997. Stochasticity and spatial resonance in interdecadal climate fluctuations. J. Climate, 10, 2299-2320.

Saravanan, R. and McWilliams, J.C., 1998. Advective ocean-atmosphere interaction: An analytical stochastic model with implications for decadal variability. J. Climate, 11, 165-188.

Simonnet, E., Ghil, M., Ide, K., Temam, R. and Wang, S., 2003a. Lowfrequency variability in shallow-water models of the wind-driven ocean circulation. Part I: Steady-state solutions. J. Phys. Oceanogr., 33, 712-728.

Simonnet, E., Ghil, M., Ide, K., Temam, R. and Wang, S., 2003b. Lowfrequency variability in shallow-water models of the wind-driven ocean circulation. Part II: Time-dependent solutions. J. Phys. Oceanogr., 33, 729752 .

Smith, R.D., Maltrud, M.E., Bryan, F.O., and Hecht, M.W., 2000. Numerical simulation of the North Atlantic Ocean at 1/10 degrees. J. Phys. Oceanogr., $30,1532-1561$.

Speich, S., Dijkstra, H. and Ghil, M., 1995. Successive bifurcations in a shallow water model applied to the wind-driven ocean circulation. Nonlin. Proc. Geophys., 2, 241-268.

Thompson, D.W.J. and Wallace, J.M., Annular modes in the extratropical circulation. Part I: Month-to-month variability. J. Climate, 13, 1000-1016.

Thompson, D.W.J., Wallace, J.M. and Hergerl, G.C., 2000. Annular modes in the extratropical circulation. Part II: Trends. J. Climate, 13, 1018-1036.

Thomson, D.J., 1982. Spectrum estimation and harmonic analysis. IEEE 
Proc., 70, 1055-1096.

Thomson, D.J., 1990. Quadratic-inverse spectrum estimates: Application to paleoclimatology. Philos. Trans. R. Soc. London, A332, 539-597.

Vautard, R., Legras, B. and Deque, M., 1988: On the source of midlatitude low-frequency variability. Part I: A statistical ap- proach to persistence. J. Atmos. Sci., 45, 2811-2843.

Wallace, J.M., 2000. North Atlantic Oscillation/annular mode: Two paradigms-one phenomenon. Quart. J. Roy. Meteor. Soc., 126, 791-805.

Wallace, J.M., Smith, C. and Jiang, Q., 1990. Spatial patterns of atmosphereocean interaction in the northern winter. J. Climate, 3, 990-998.

Weaver, A.J., Marotzke, J., Cummins, P.F. and Sarachik, E.S., 1993. Stability and variability of the thermohaline circulation. J. Phys. Oceanogr., 23, 3960.

Weng, W. and Neelin, J.D., 1998. On the role of ocean-atmosphere interaction in midlatitude decadal variability. Geophys. Res. Let., 25, 167-170. 


\section{Figure Captions}

Fig. 1. Jet-center position (degrees $\mathrm{N}$ ) of the atmosphere-only model as a function of the barotropic spin-down time scale $k^{-1}$ (days), adapted from Kravtsov et al. (2005a): "+" and solid curve - high-latitude state, "x" and dashed curve - low-latitude state.

Fig. 2. Atmospheric climatology. (a) Barotropic zonal velocity $\left(\mathrm{m} \mathrm{s}^{-1}\right), C I=$ 4; and (b) atmospheric temperature $\left({ }^{\circ} \mathrm{C}\right), C I=6$. Negative contours dashed, zero contour dotted; heavy solid lines mark ocean boundaries. The horizontal heavy black line in this and subsequent plots marks the location of the $45 \mathrm{~N}$ latitude.

Fig. 3. Mixed-layer climatology. (a) $\operatorname{SST}\left({ }^{\circ} \mathrm{C}\right), C I=3$; (b) surface heat flux into the ocean $F_{\mathrm{s}}\left(\mathrm{W} \mathrm{m}^{-2}\right), C I=10$; (c) Ekman pumping $\left(\mathrm{m} \mathrm{s}^{-1}\right), C I=10^{-6}$; (d) interior entrainment mass flux $\left(\mathrm{m} \mathrm{s}^{-1}\right), C I=10^{-7}$. Negative contours dashed, zero contour dotted.

Fig. 4. Ocean's climatological mass transports (in Sv; $1 \mathrm{~Sv} \equiv 10^{6} \mathrm{~m}^{3} \mathrm{~s}^{-1}$ ) in the (a) upper layer $\left(\Psi_{1}\right), C I=5$; (b) middle layer $\left(\Psi_{2}\right), C I=5$; (c) lower layer $\left(\Psi_{3}\right), C I=5 ;(\mathrm{d})$ barotropic transport $\left(\Psi_{\text {barotr }} \equiv \Psi_{1}+\Psi_{2}+\Psi_{3}\right), C I=10$.

Fig. 5. Time series of key model quantities (40-day averages). Thin solid lines show: (a) atmospheric jet position (degrees $\mathrm{N}$ ), defined as the latitude of maximum zonal-mean barotropic velocity (see Fig. 1); and (b) ocean's kinetic energy $E_{\mathrm{k}, 1}\left(\mathrm{~cm}^{2} \mathrm{~s}^{-2}\right)$. Heavy solid lines show 5-30-yr band-pass filtered time series. 
Fig. 6. Probability density function (PDF) of jet-position time series in Fig. 5 a.

Fig. 7. Fourier spectra of time series in Figs. 5a,b, as well as those of accompanying coupled and uncoupled integrations (see text for details).

Fig. 8. (a) Synthetic jet-position time series obtained by retaining the lowlatitude state time dependence only (see text for details); (b) Fourier spectrum of synthetic time series shown in panel (a).

Fig. 9. Lagged regression of atmospheric barotropic zonal velocity onto the normalized time series of band-pass filtered ocean kinetic energy (Fig. 5b, heavy solid line), multiplied by -1 . Units and contour interval are given in the figure legend, lag value is given in the heading of each panel. Lag-0 corresponds to the minimum of kinetic energy, while positive lags correspond to $E_{\mathrm{k}, 1}$ leading the atmospheric barotropic velocity evolution. Negative contours dashed, zero contour dotted. Shading denotes values statistically significant at the $5 \%$ level with respect to a fairly sophisticated null hypothesis (see text). Geometry not to scale.

Fig. 10. Same as in Fig. 9, but for the atmospheric temperature field.

Fig. 11. Same as in Fig. 9, but for the Ekman pumping $w_{\mathrm{E}}$.

Fig. 12. Same as in Fig. 9, but for the ocean's upper-layer mass transport $\Psi_{1}$.

Fig. 13. Same as in Fig. 9, but for the SST field.

Fig. 14. Same as in Fig. 9, but for the surface heat flux into the ocean $F_{\mathrm{s}}$ (continuous contours thus denote the flux into ocean). 


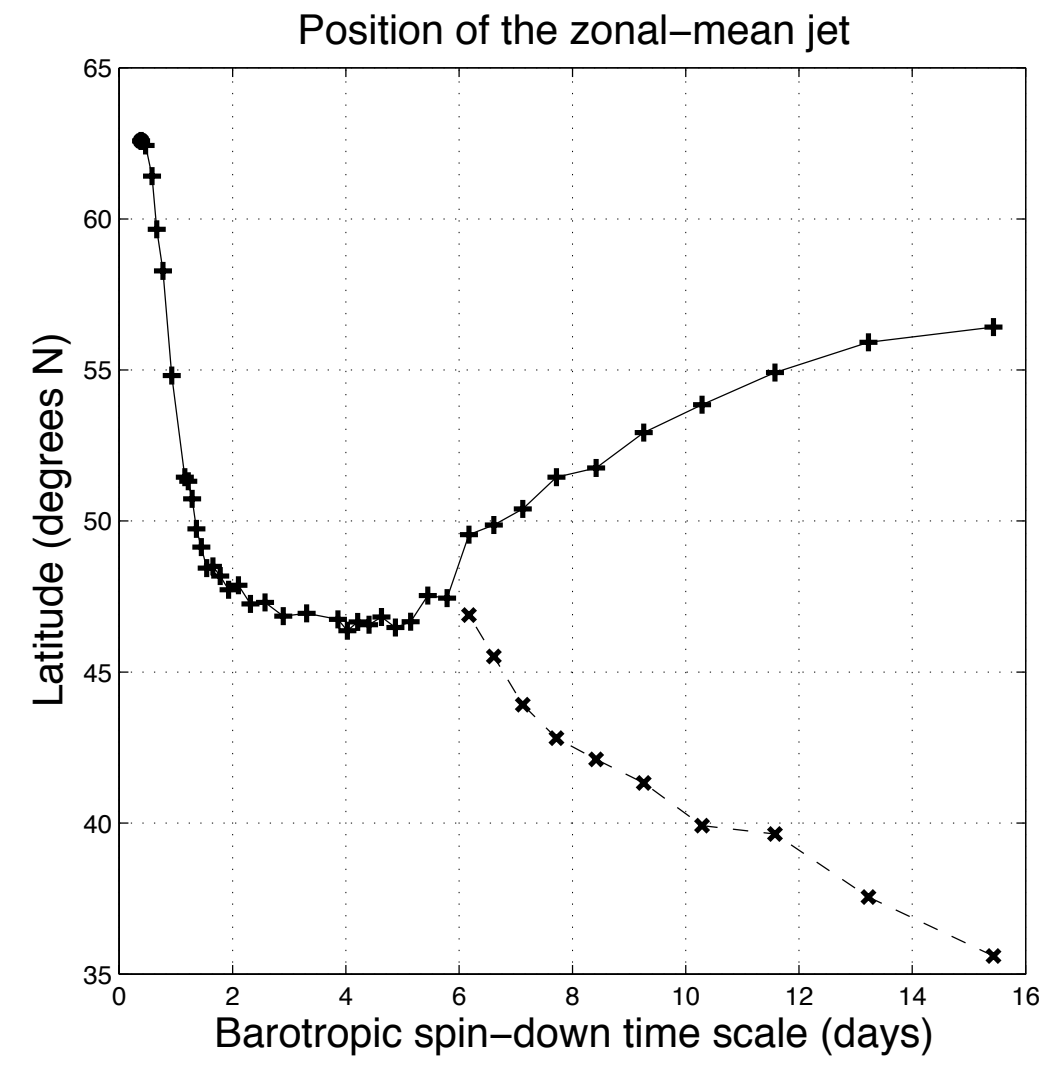

Fig. 1. Jet-center position (degrees $\mathrm{N}$ ) of the atmosphere-only model as a function of the barotropic spin-down time scale $k^{-1}$ (days), adapted from Kravtsov et al. (2005a): "+" and solid curve - high-latitude state, "x" and dashed curve - low-latitude state. 
(a)

Barotropic U

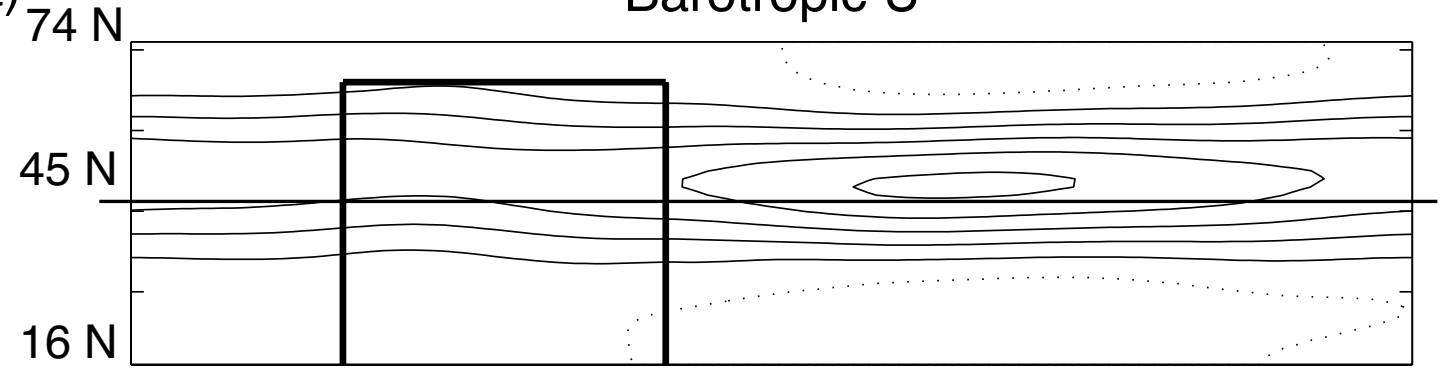

(b) $74 \mathrm{~N} \quad$ Atmospheric temperature

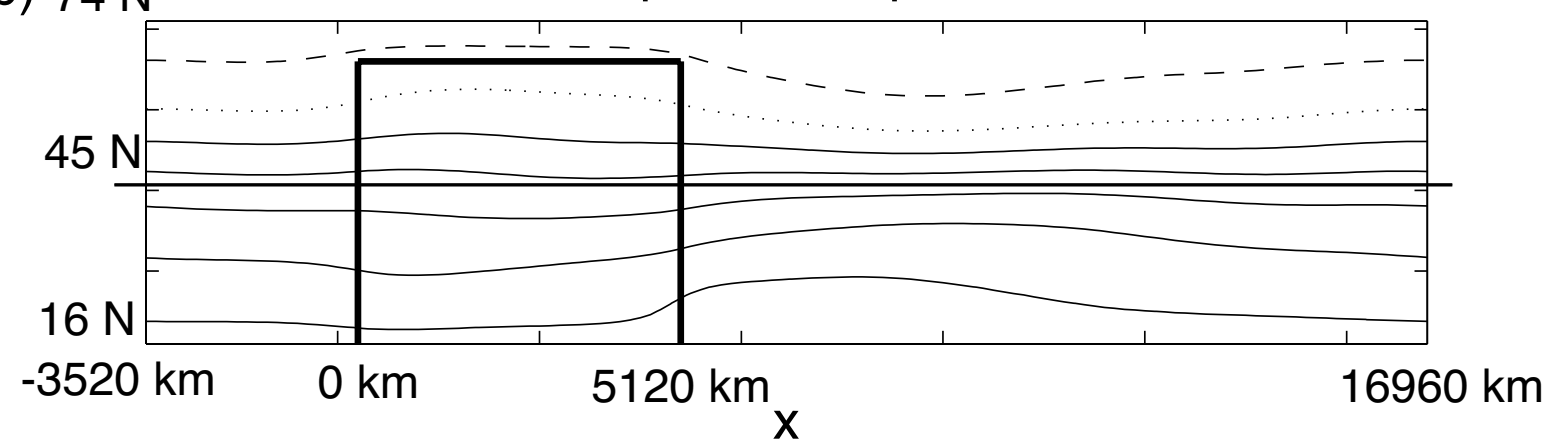

Fig. 2. Atmospheric climatology. (a) Barotropic zonal velocity $\left(\mathrm{m} \mathrm{s}^{-1}\right), C I=4$; and (b) atmospheric temperature $\left({ }^{\circ} \mathrm{C}\right), C I=6$. Negative contours dashed, zero contour dotted; heavy solid lines mark ocean boundaries. The horizontal heavy black line in this and subsequent plots marks the location of the $45 \mathrm{~N}$ latitude. 
(a)

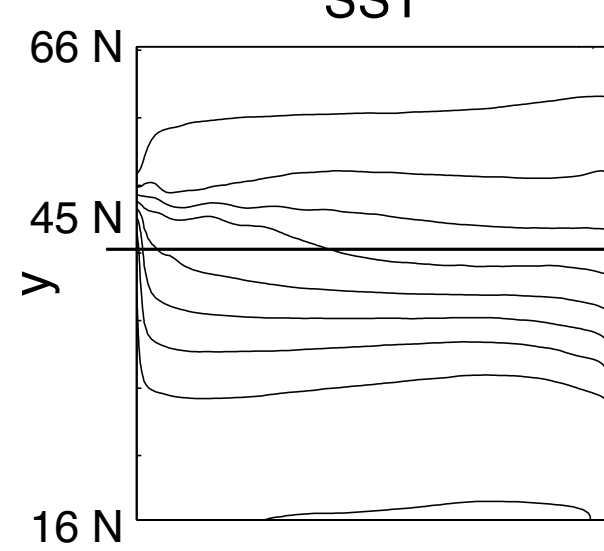

(c)

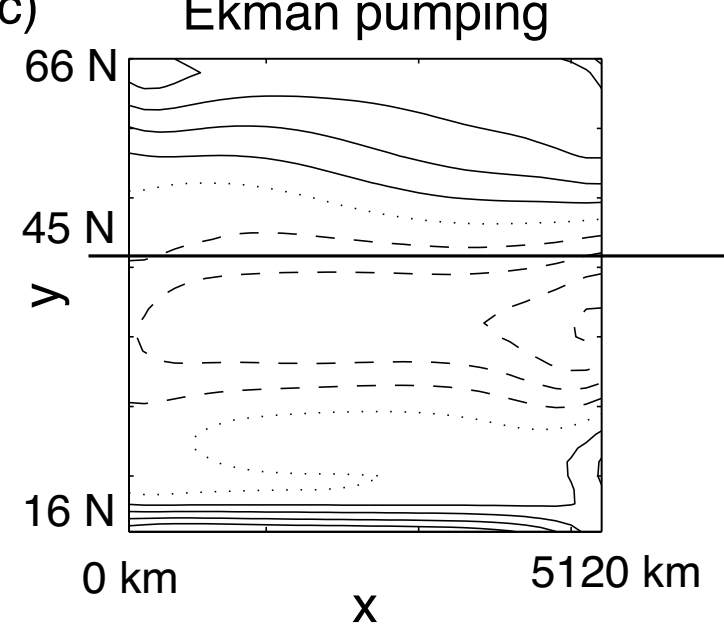

(b) Surface heat flux $\left(\mathrm{F}_{\mathrm{s}}\right)$

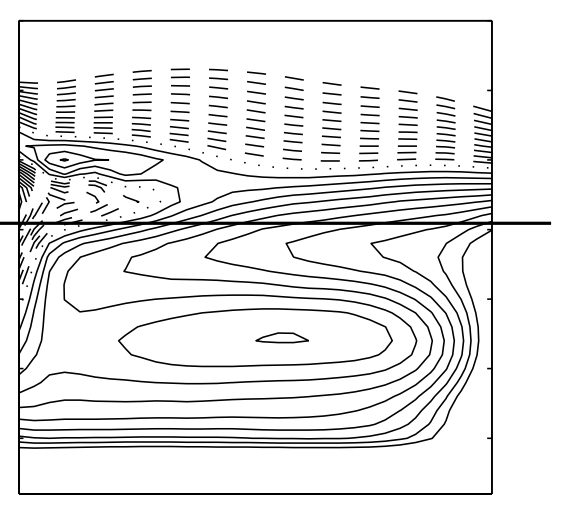

(d) Entrainment flux

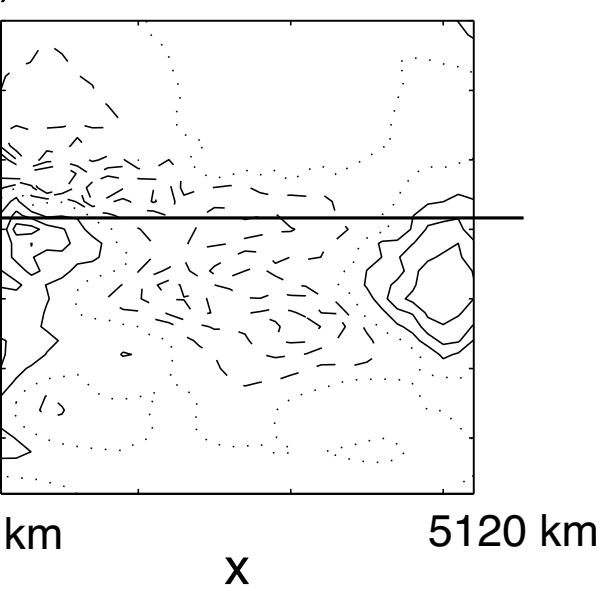

Fig. 3. Mixed-layer climatology. (a) SST $\left({ }^{\circ} \mathrm{C}\right), C I=3$; (b) surface heat flux into the ocean $F_{\mathrm{s}}\left(\mathrm{W} \mathrm{m}^{-2}\right), C I=10$; (c) Ekman pumping $\left(\mathrm{m} \mathrm{s}^{-1}\right), C I=10^{-6}$; (d) interior entrainment mass flux $\left(\mathrm{m} \mathrm{s}^{-1}\right), C I=10^{-7}$. Negative contours dashed, zero contour dotted. 
(a)

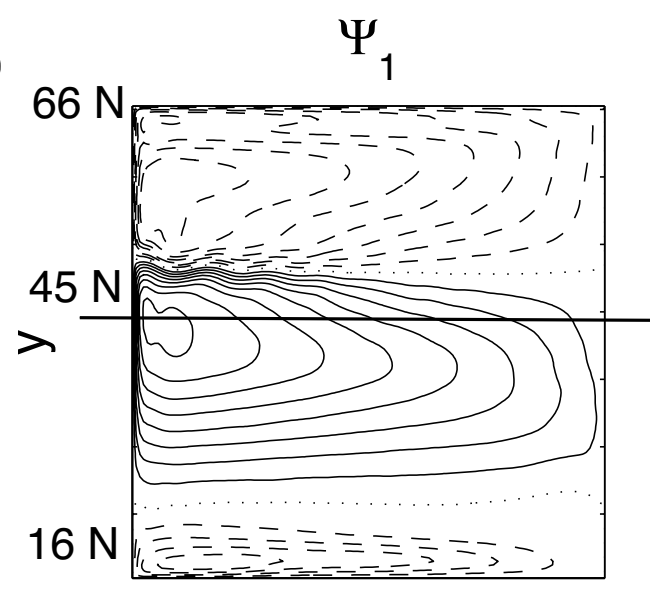

(c)

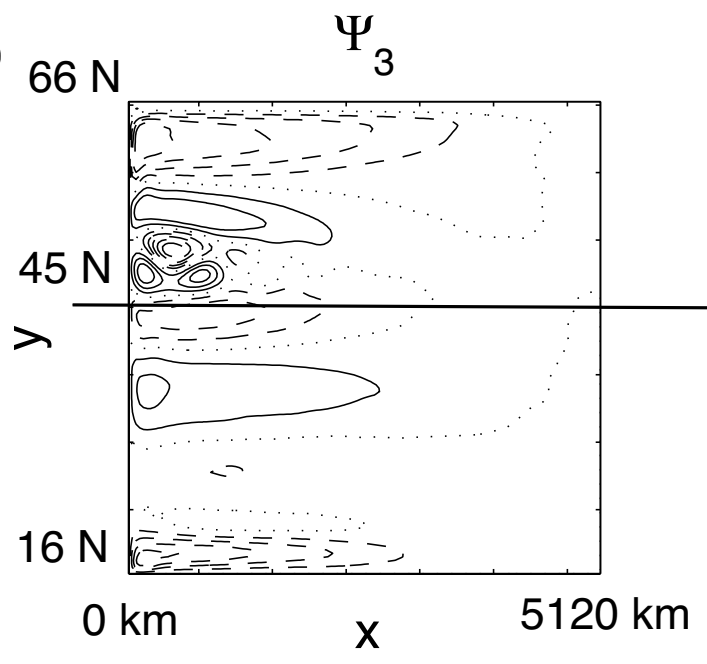

(b)

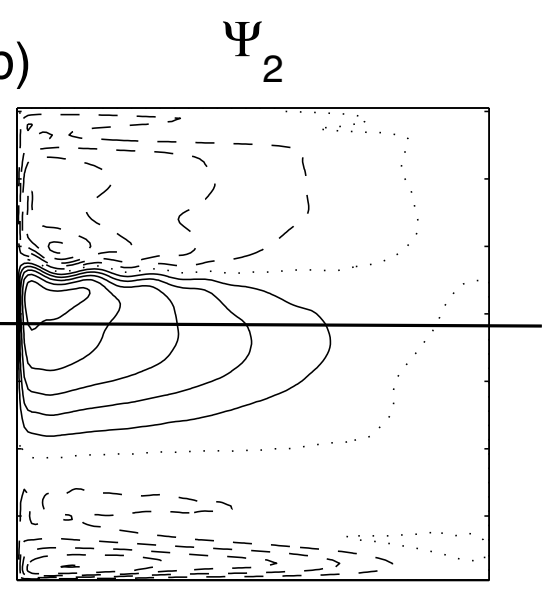

(d)
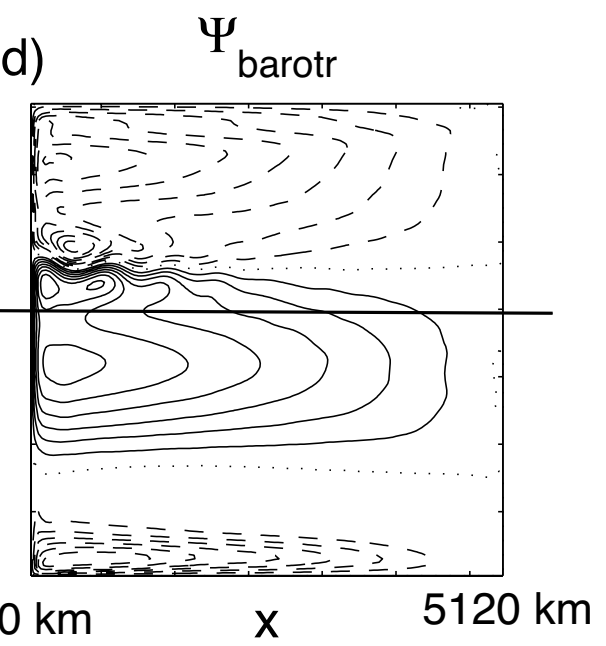

Fig. 4. Ocean's climatological mass transports (in Sv; $1 \mathrm{~Sv} \equiv 10^{6} \mathrm{~m}^{3} \mathrm{~s}^{-1}$ ) in the (a) upper layer $\left(\Psi_{1}\right), C I=5$; (b) middle layer $\left(\Psi_{2}\right), C I=5$; (c) lower layer $\left(\Psi_{3}\right)$, $C I=5$; (d) barotropic transport $\left(\Psi_{\text {barotr }} \equiv \Psi_{1}+\Psi_{2}+\Psi_{3}\right), C I=10$. 


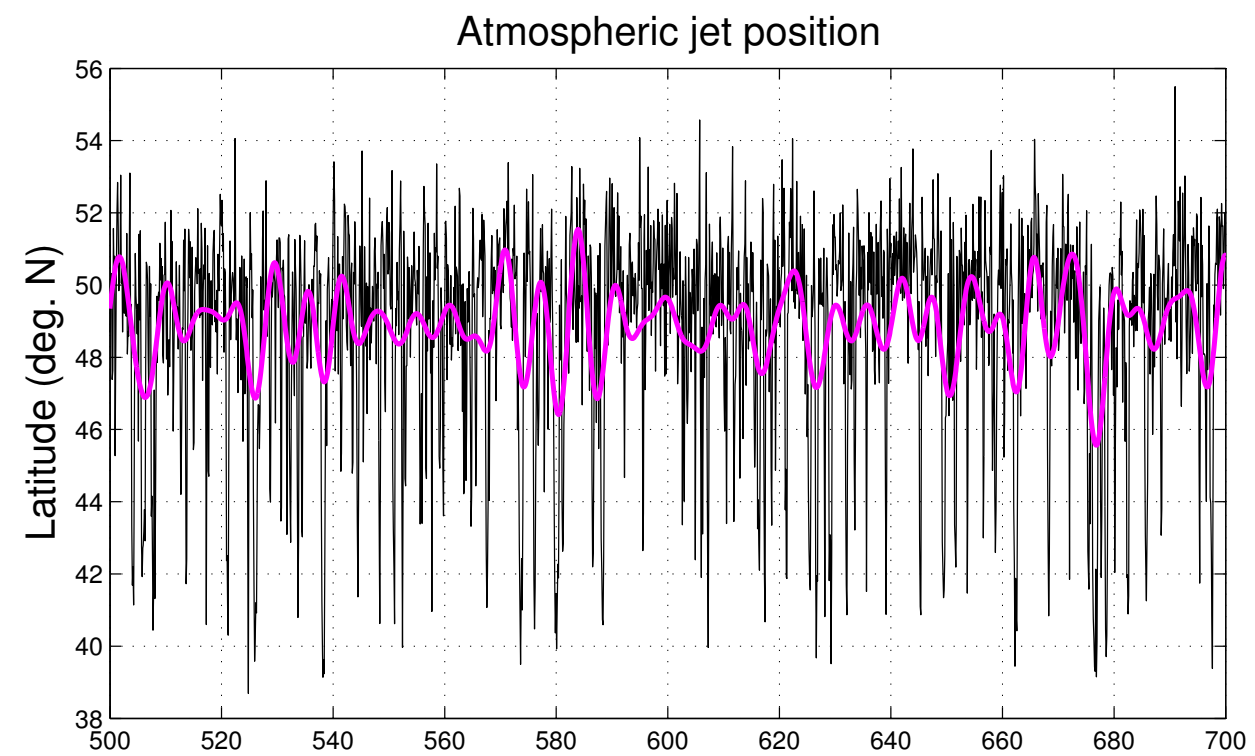

(a)

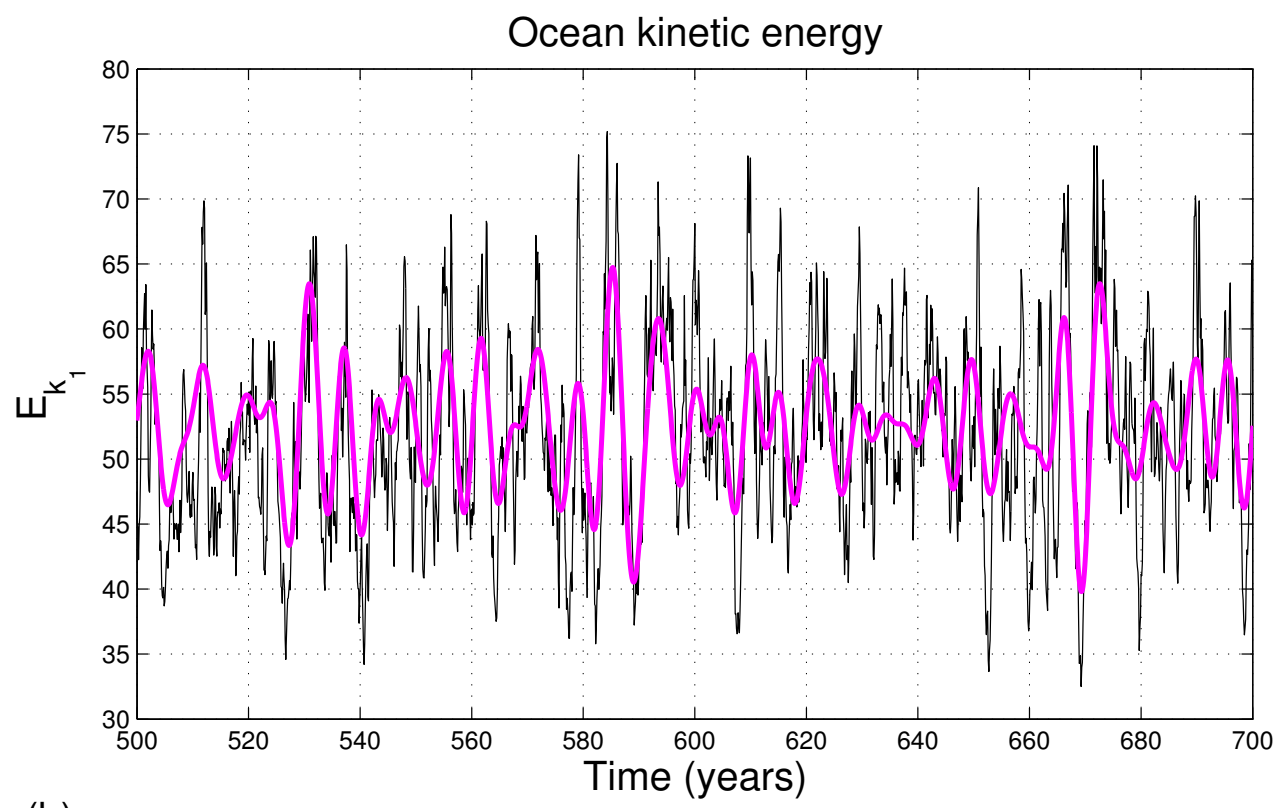

(b)

Fig. 5. Time series of key model quantities (40-day averages). Thin solid lines show: (a) atmospheric jet position (degrees $\mathrm{N}$ ), defined as the latitude of maximum zonal-mean barotropic velocity (see Fig. 1); and (b) ocean's kinetic energy $E_{\mathrm{k}, 1}\left(\mathrm{~cm}^{2} \mathrm{~s}^{-2}\right)$. Heavy solid lines show 5-30-yr band-pass filtered time series. 


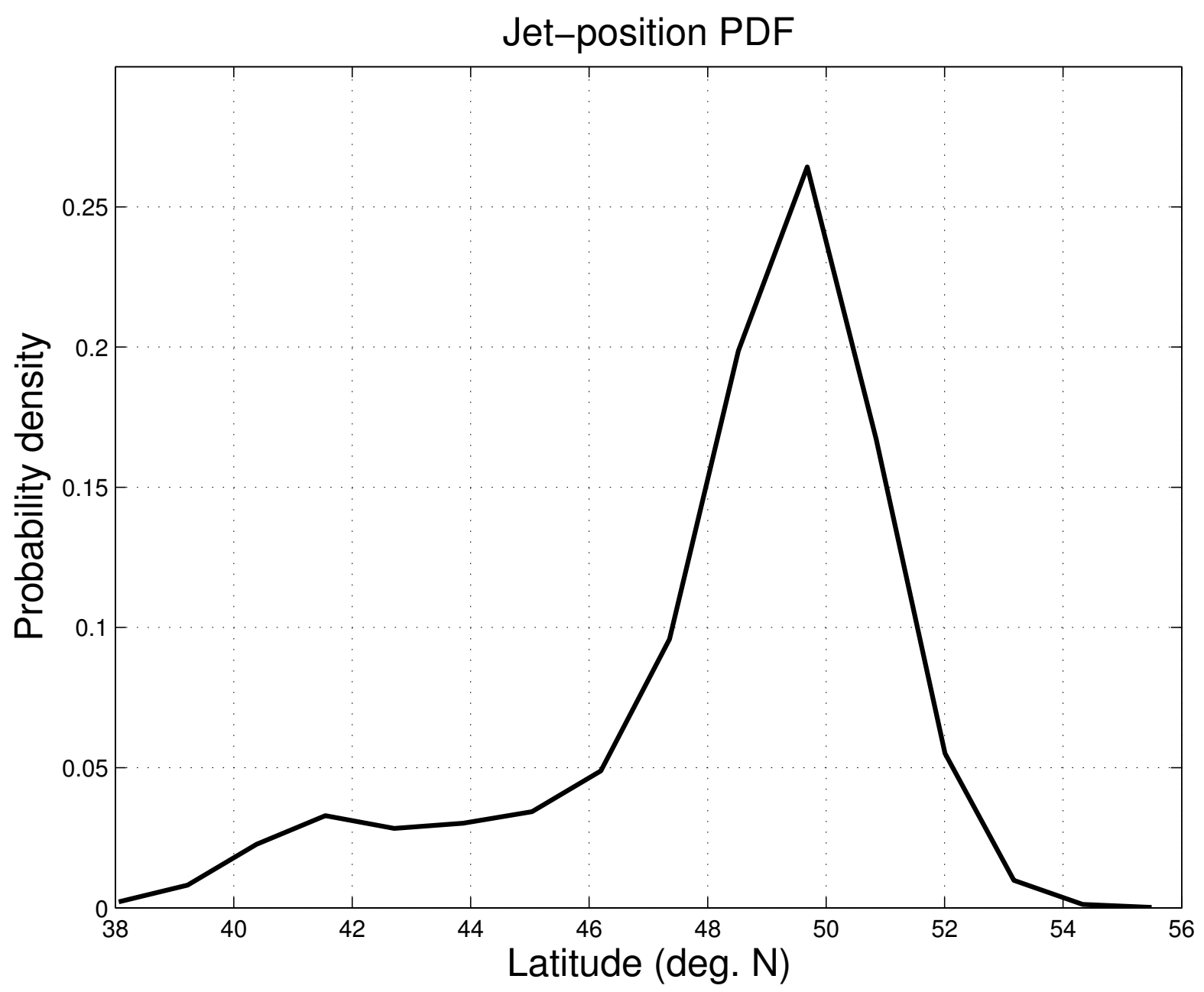

Fig. 6. Probability density function (PDF) of jet-position time series in Fig. 5a. 


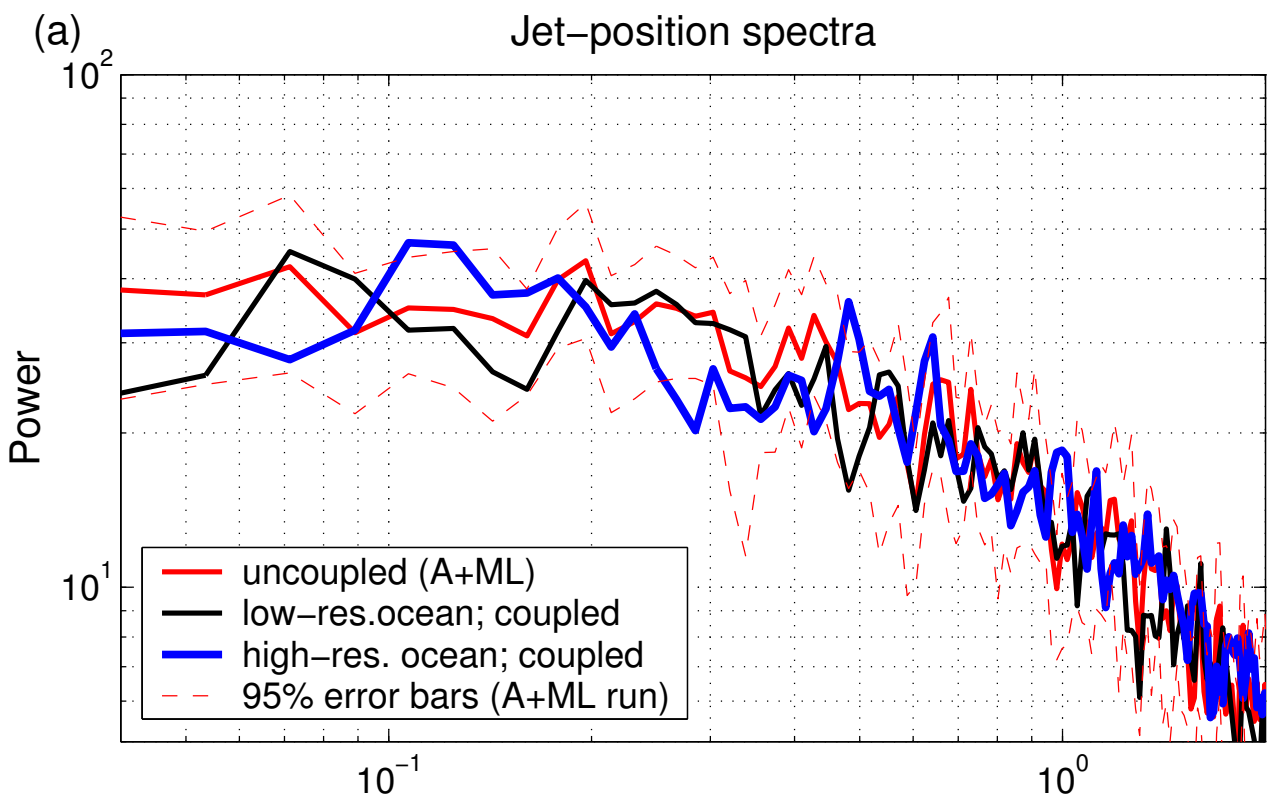

(b) Ocean kinetic energy spectra

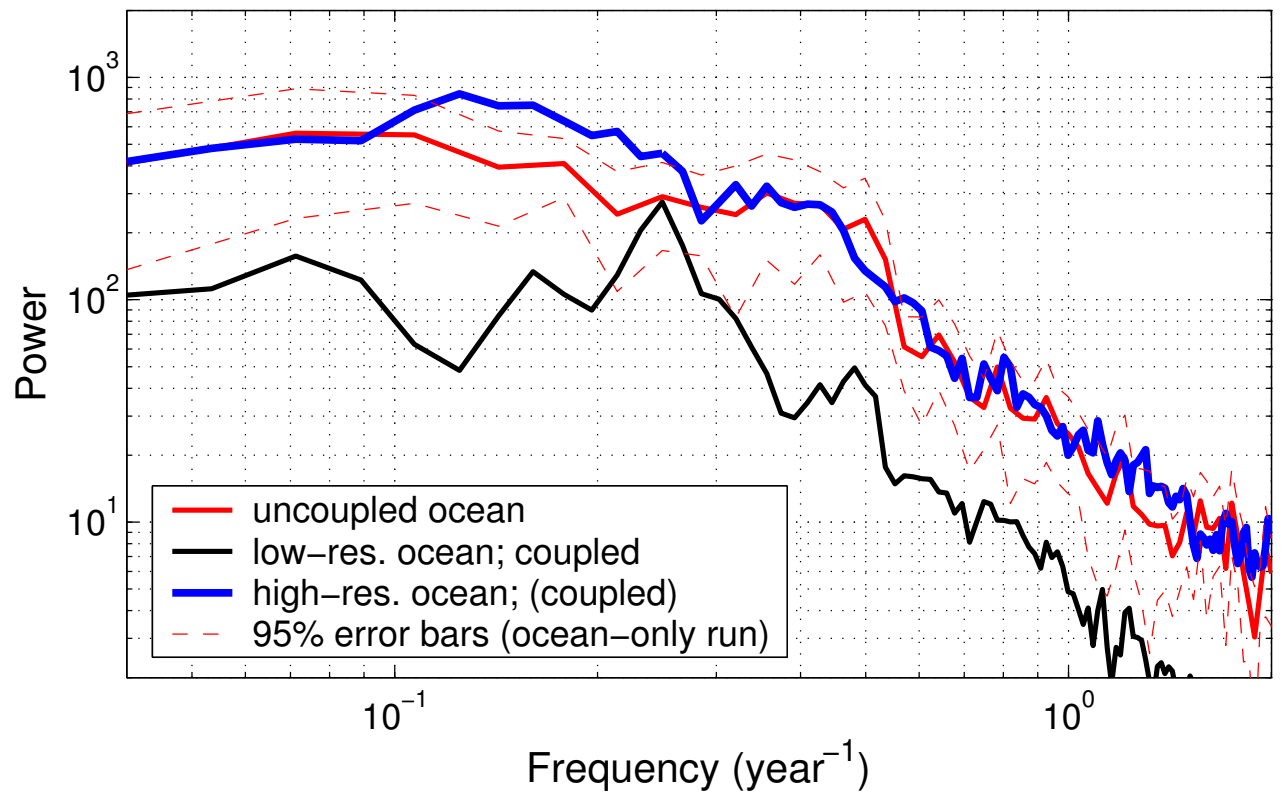

Fig. 7. Fourier spectra of time series in Figs. 5a,b, as well as those of accompanying coupled and uncoupled integrations (see text for details). 

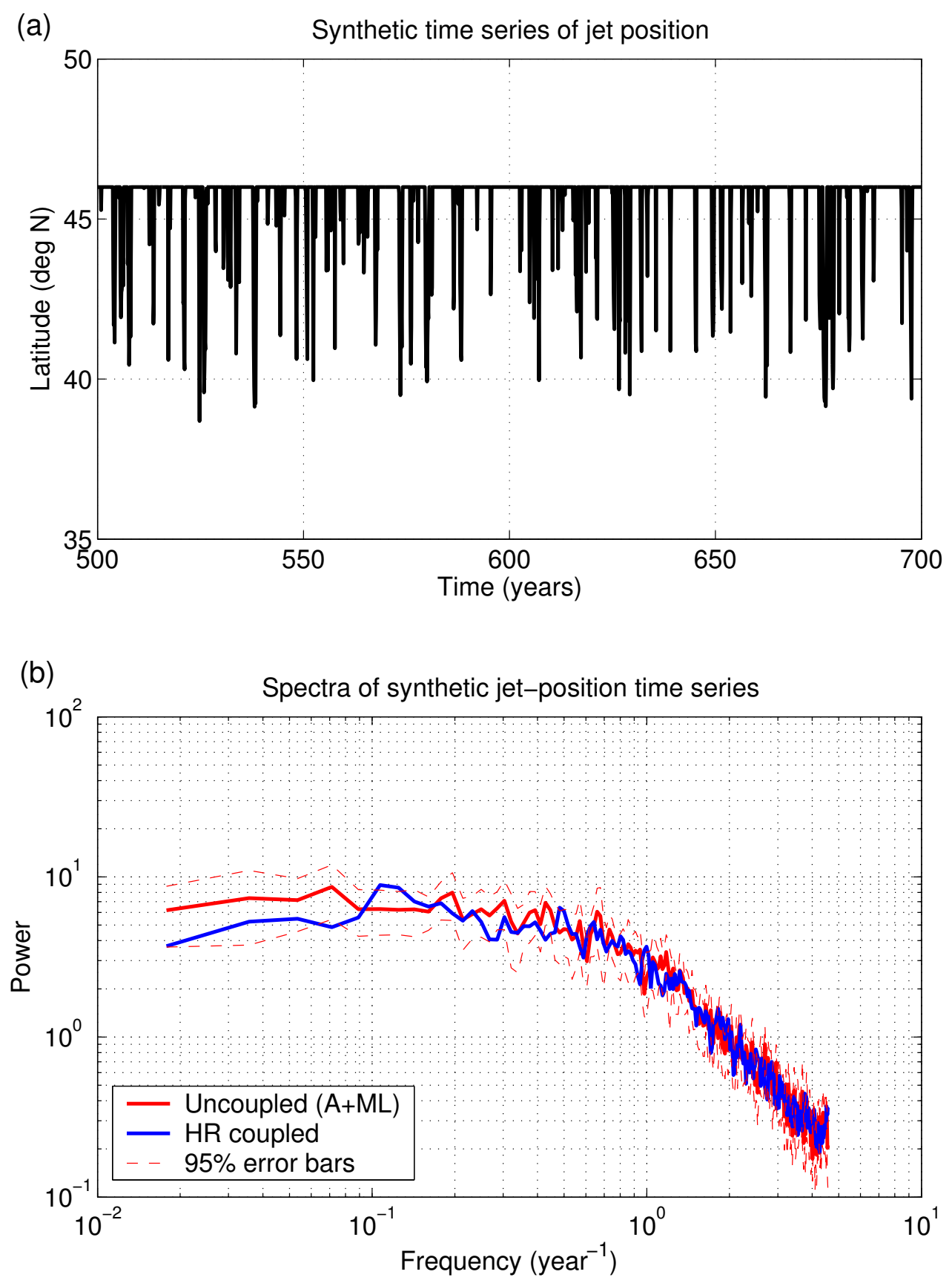

Fig. 8. (a) Synthetic jet-position time series obtained by retaining the low-latitude state time dependence only (see text for details); (b) Fourier spectrum of synthetic time series shown in panel (a). 

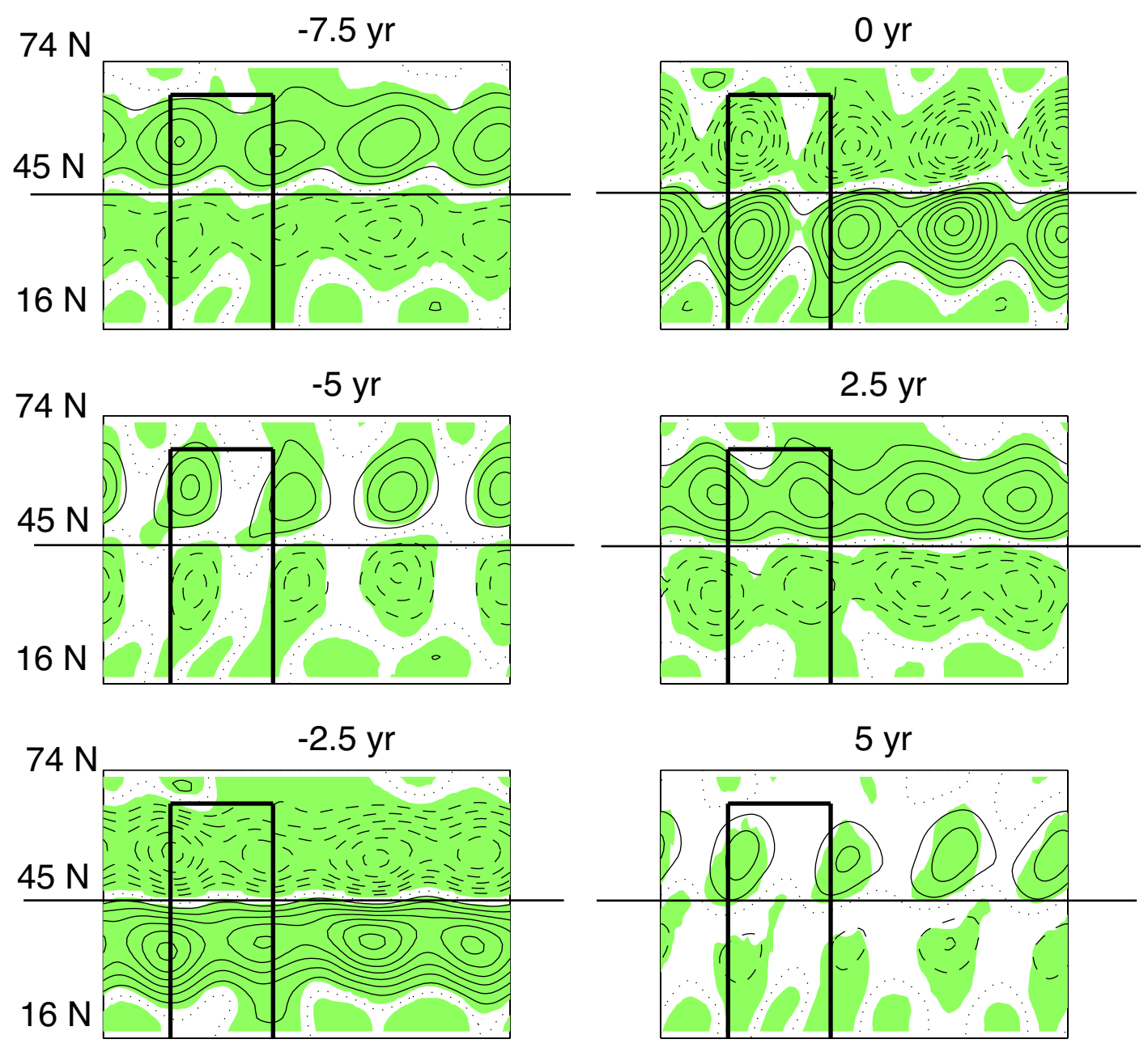

\section{Barotropic zonal velocity $\left(\mathrm{Cl}=0.16 \mathrm{~m} \mathrm{~s}^{-1}\right)$}

Fig. 9. Lagged regression of atmospheric barotropic zonal velocity onto the normalized time series of band-pass filtered ocean kinetic energy (Fig. 5b, heavy solid line), multiplied by -1 . Units and contour interval are given in the figure legend, lag value is given in the heading of each panel. Lag-0 corresponds to the minimum of kinetic energy, while positive lags correspond to $E_{\mathrm{k}, 1}$ leading the atmospheric barotropic velocity evolution. Negative contours dashed, zero contour dotted. Shading denotes values statistically significant at the $5 \%$ level with respect to a fairly sophisticated null hypothesis (see text). Geometry not to scale. 

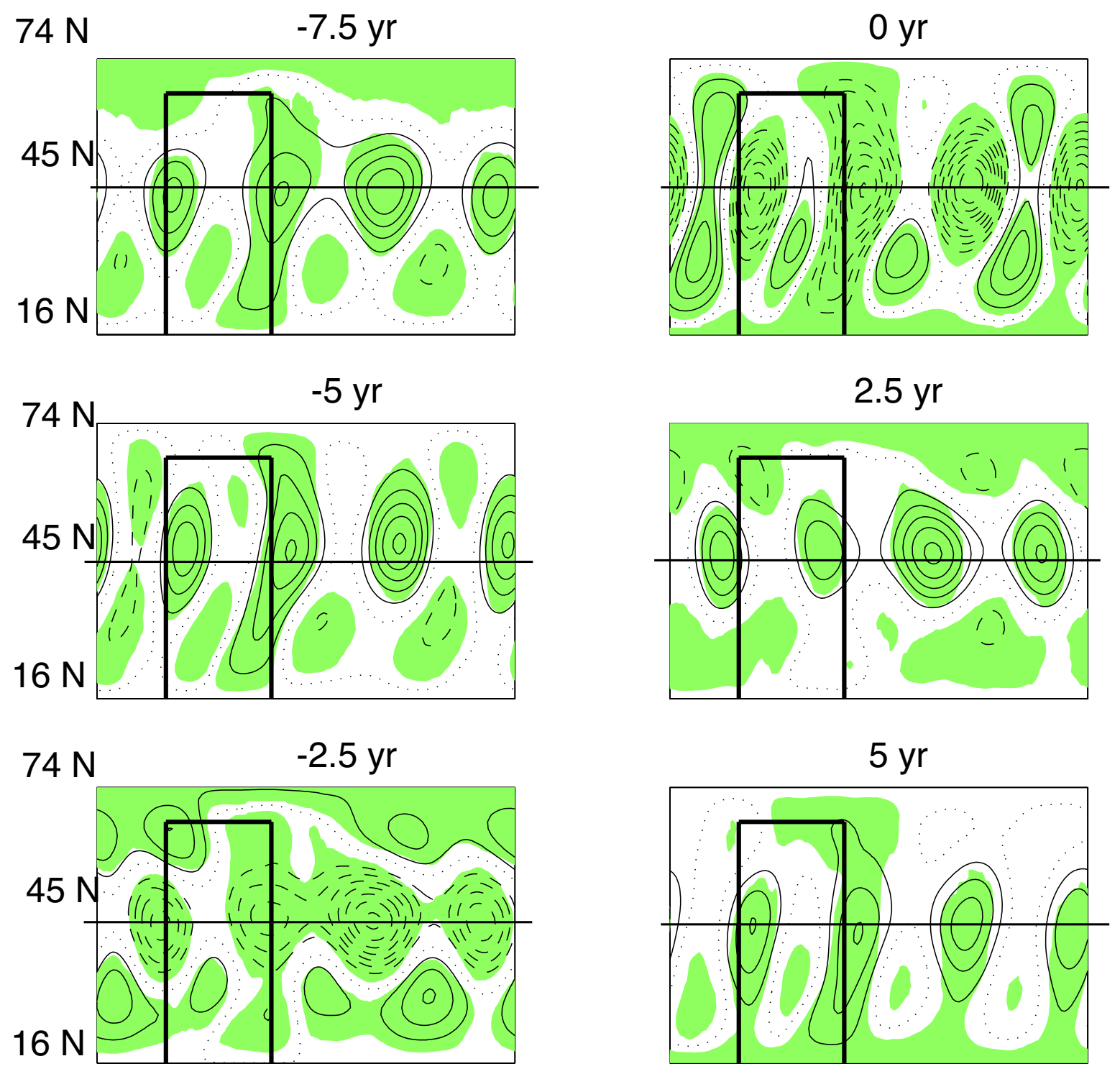

\section{Atmospheric temperature $(\mathrm{Cl}=0.1$ degrees $\mathrm{C})$}

Fig. 10. Same as in Fig. 11, but for the atmospheric temperature field. 

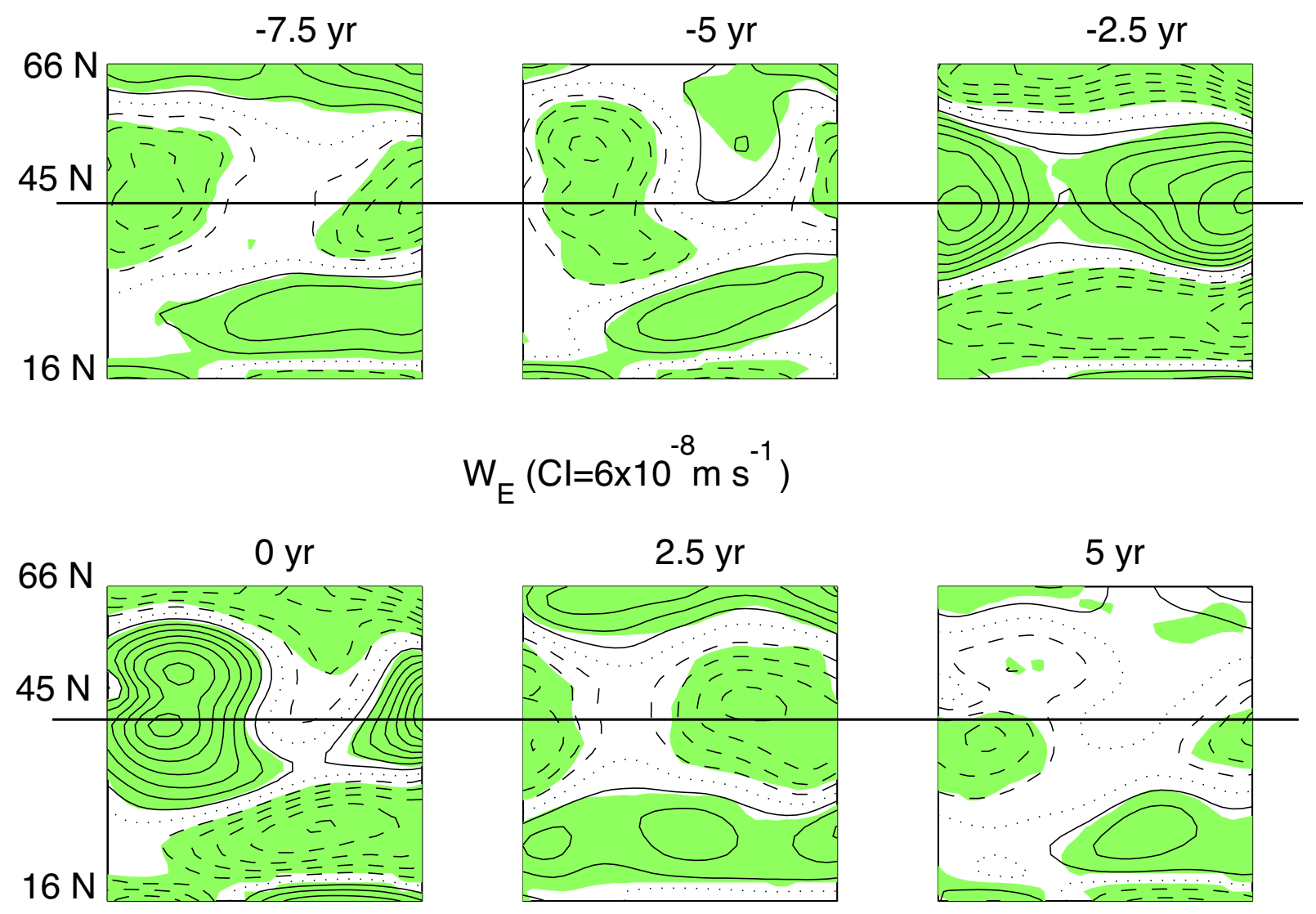

Fig. 11. Same as in Fig. 11, but for the Ekman pumping $w_{\mathrm{E}}$. 


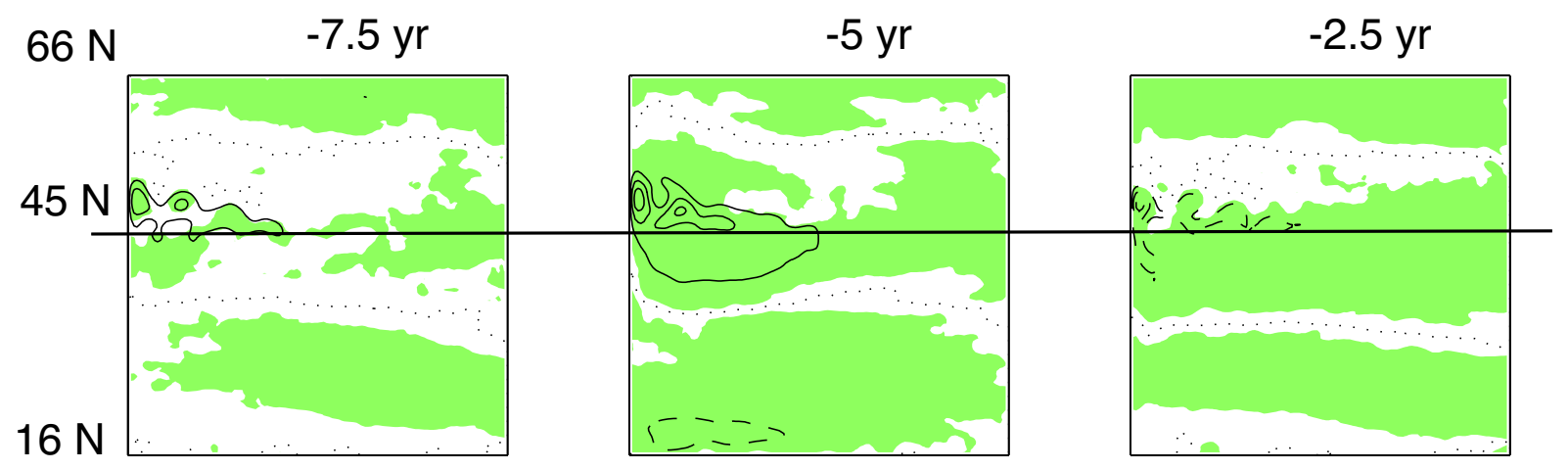

$$
\Psi_{1}(\mathrm{Cl}=2 \mathrm{~Sv})
$$

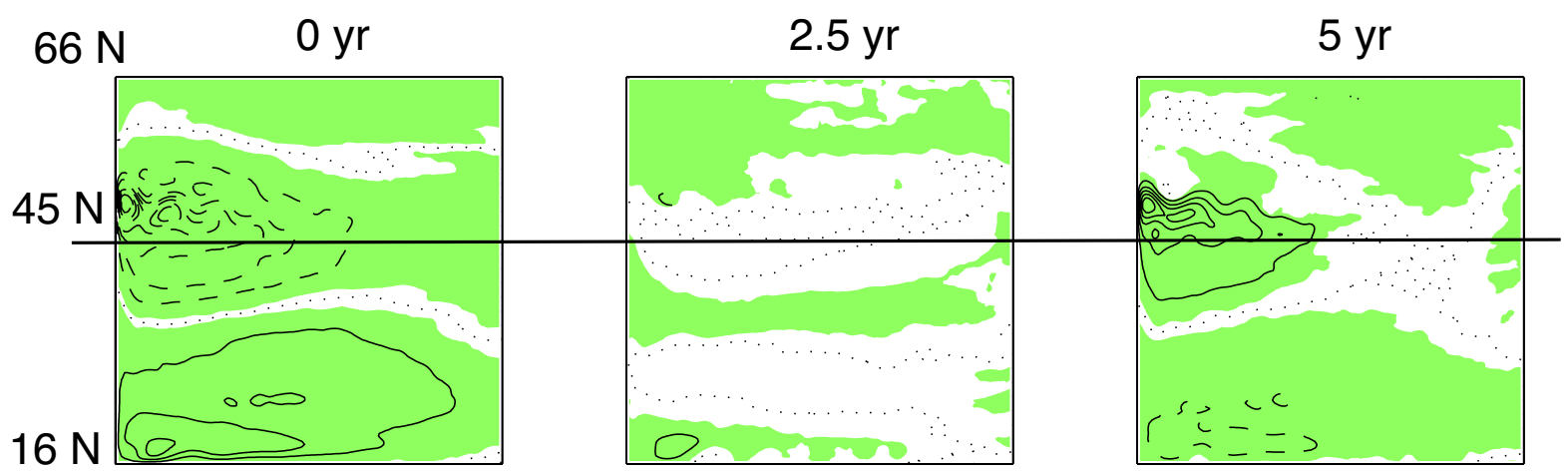

Fig. 12. Same as in Fig. 11, but for the ocean's upper-layer mass transport $\Psi_{1}$. 


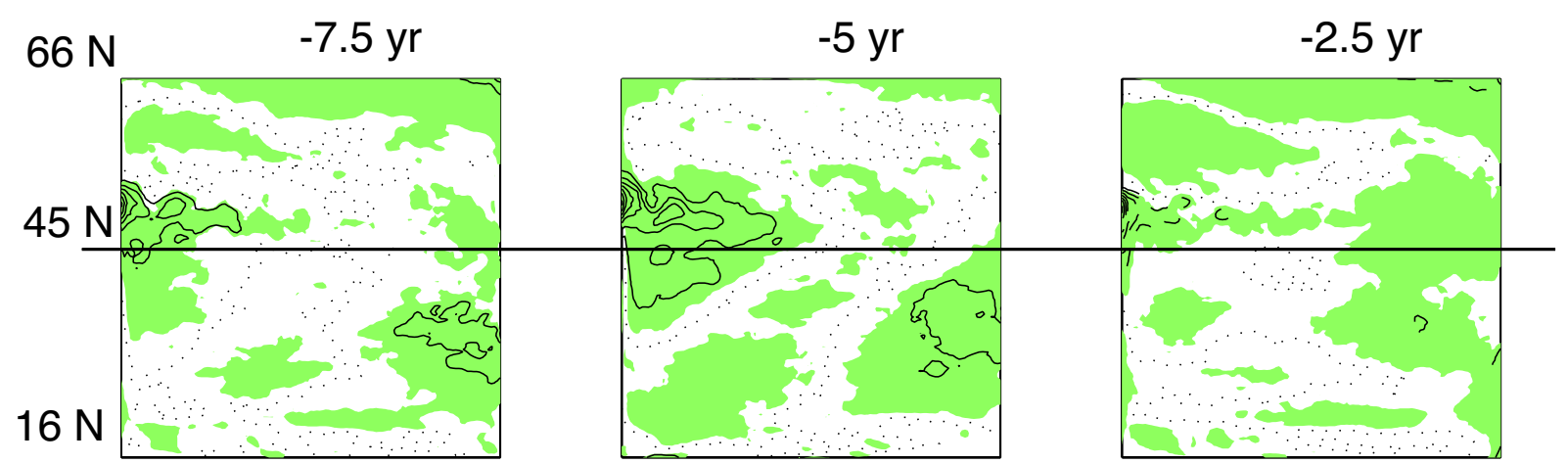

SST ( $\mathrm{Cl}=0.2$ degrees $\mathrm{C}$ )

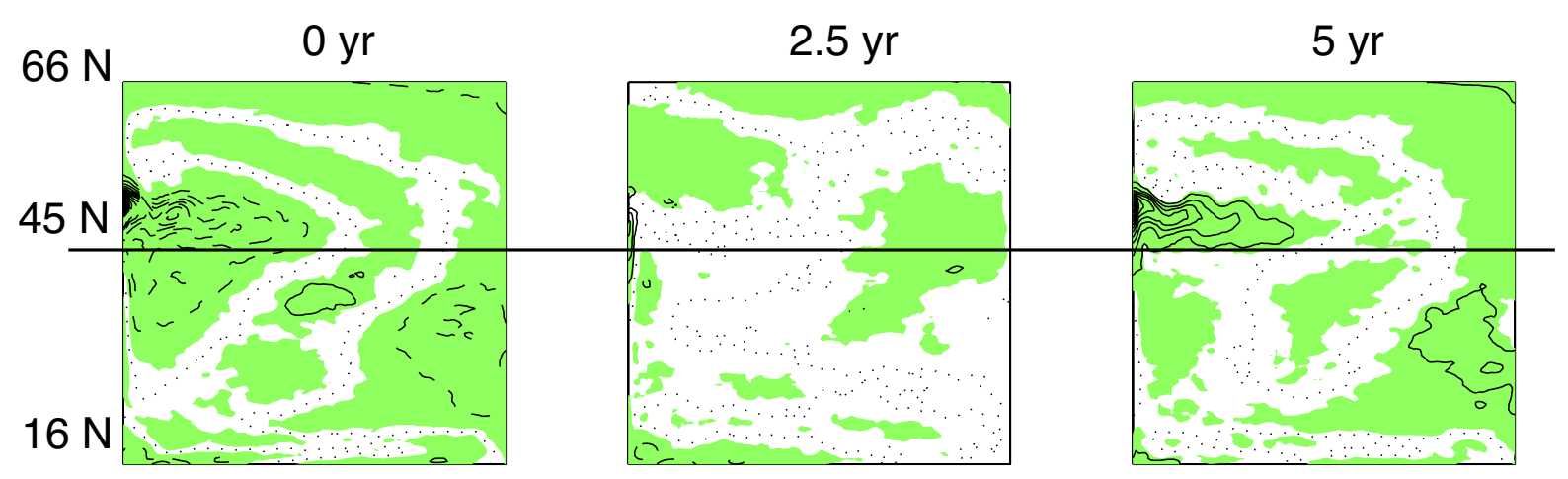

Fig. 13. Same as in Fig. 11, but for the SST field. 


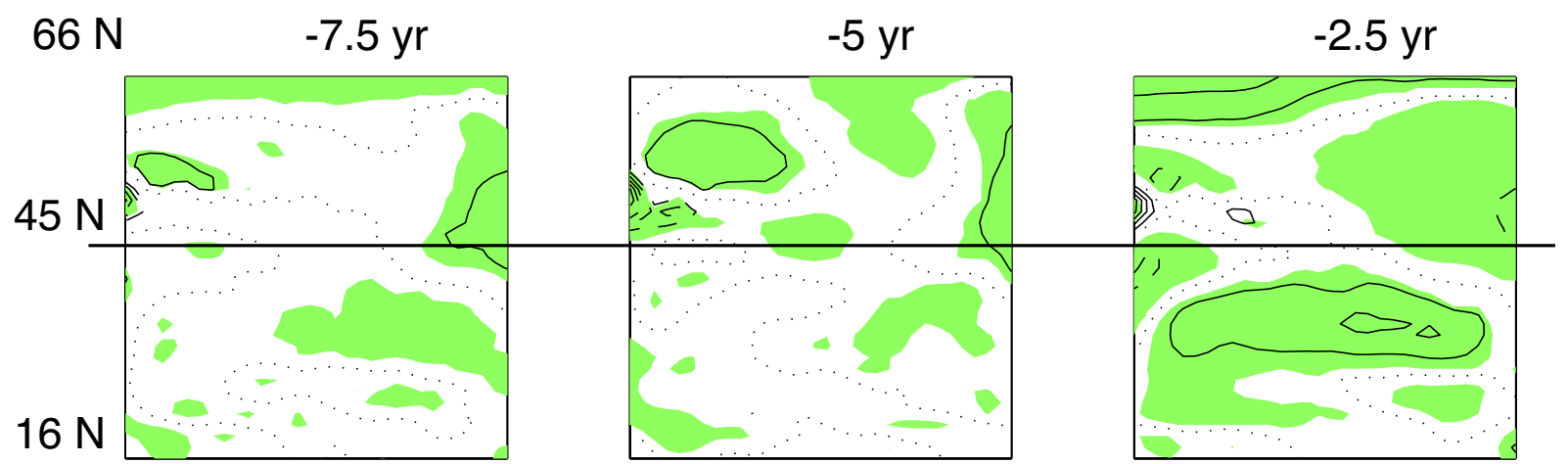

Surface heat flux $\left(\mathrm{Cl}=3 \mathrm{~W} \mathrm{~m}^{-2}\right)$

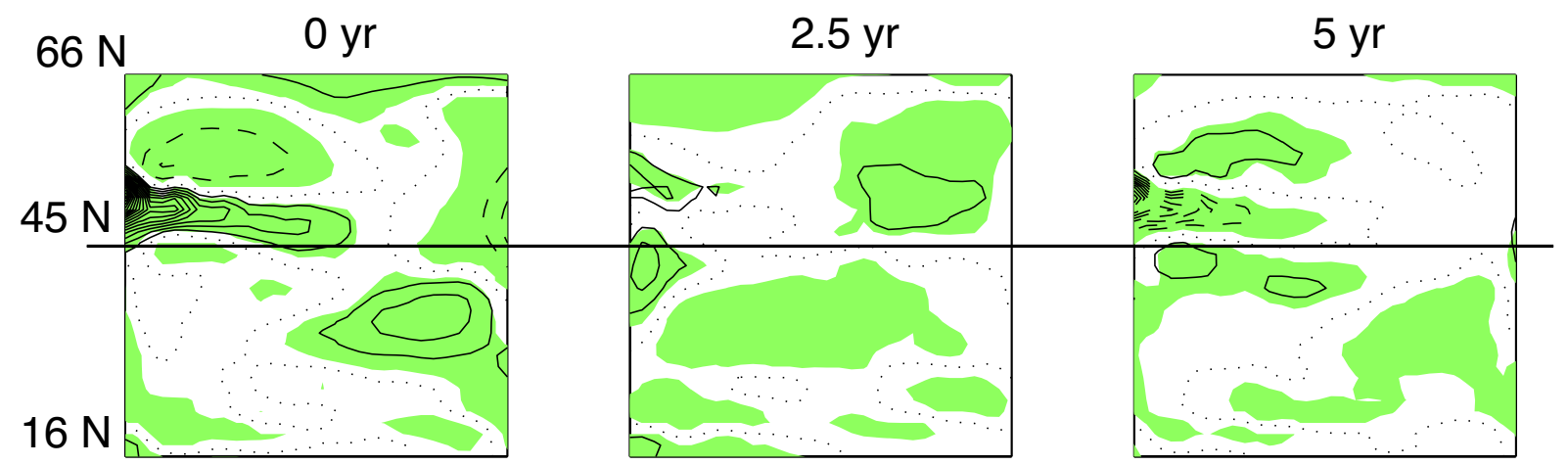

Fig. 14. Same as in Fig. 11, but for the surface heat flux into the ocean $F_{\mathrm{s}}$ (continuous contours thus denote the flux into ocean). 